\title{
CROSSING THE NORTH AFRICAN AND SOUTH AFRICAN OSTRICH.
}

\author{
BY J. E. DUERDEN, M.Sc., Рн.D.,
}

Professor.of Zoology, Rhodes University College, Grahamstown; Offcerin-Charge, Ostrich Investigations, Grootfontein School of Agriculture, Middelburg, C. P., South Africa.

(With Plate VII, and Two Text-figures.)

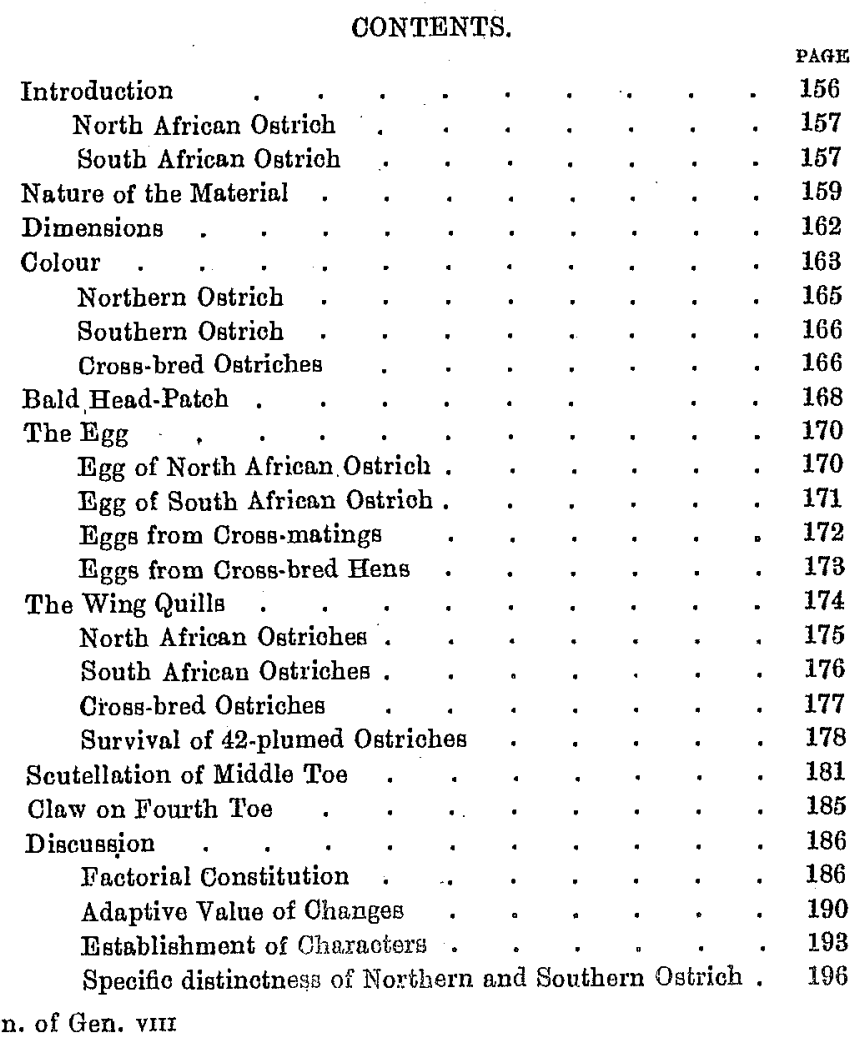




\section{INTRODUCTION.}

THe continent of Africa, with the adjoining parts of Arabia, Palestine and Asia Minor, is the natural home of the ostrich genus Struthio. Beyond the confines of Africa however the wild bird is now extremely rare, if it exists at all; while in Africa it is slowly passing away as the continent becomes occupied by the white settler. The domesticated bird on the other hand has greatly increased in number during the fifty years of ostrich farming, amounting to near one million in 1913 , though since considerably reduced owing to the less demand for plumage as a result of the prolonged war.

Zoologists recognise four species of the two-toed ostrich: the North African ostrich, Struthio camelus Linn., the South African ostrich S. australis Gurney, the East.African ostrich, S. massaicus Naumann and the Somali ostrich, S. molybdophanes Reichenow. The two last mentioned are not however well-established species, appearing to represent intermediate types of the other two. On the other hand the northern and the southern birds have well-defined characteristics separating them, connected with size, colour, nature of the egg and other minor features. Observing them side by side no one would hesitate in assigning them specific distinction.

Recently a unique opportunity has presented itself for studying numbers of the northern and southern ostrich under similar conditions, and also the behaviour of their characters when the two are crossed. In 1912 the Government of the Union of South Africa imported 132 specimens of the North African ostrich from Nigeria', with the object of possibly improving the domesticated strains built up from the original South African wild bird. The imported birds were stationed at the Grootfontein School of Agriculture, and the breeding experiments to be conducted with them were placed in charge of the writer.

The main object of the investigations is the practical one of determining to what degree the plumage of the southern bird can be improved by crossing with the northern, but in the course of the worls many other questions have arisen which have an interest to students of genetics generally. The experiments have been in progress for over four years, and during that period about a hundred cross-bred chicks $\left(F_{1}\right)$ have been hatched as well as a score or so of pure North African chicks; at the present time some of the first crosses have reached the age at which they are beginning to breed, but only two chicks belonging

1 Report on the North African Ostriches. imported into South Africa in 1912. Union of South Africa, Department of Agriculture, Pretoria, No. 2, 1916. 
to the second hybrid generation ( $\left.F_{2}\right)$ have yet been reared. The earlier matings were carried out with whichever of the northern birds happened to attain sexual maturity, irrespective of their plumage qualities or other characters; but with the abundant material now available crosses are made with a definite purpose in view. The long period between the maturity of one generation and the next, usually between three and four years, necessarily renders progress slow ${ }^{1}$.

The distinguishing characters of the northern and the southern ostrich are as follows:

A. The North African Ostrich, Struthio camelus Linn. The species is larger and stronger than the South African bird, the head reaching about $8 \frac{1}{4}$ feet from the ground; the length of the body from the tip of the beak to the end of the tail is about 8 feet, and the total weight about 275 lbs. The neck is also longer, about $3 \frac{1}{2}$ feet in length, and the body feathers extend upwards for about 13 feet. The legs are longer, thicker and more robust, the knee joint being at least 4 feet from the ground, and the feet are larger; a claw is sometimes present on the small toe and the scales over the large toe may show one or, rarely, two breaks.

The number of wing plumes, or remiges, is about 36 to each wing, but varies from 33 to 39 .

The colour of the skin in immature birds of both sexes, as well as of mature hens, is a creamy yellow, while the mature cock is bright red or scarlet on the legs, head and neck, and red or pink over the body generally.

The crown of the head has a bald patch, either single or partly divided (Text-fig. 1, p. 158).

The egg is smooth, as if polished, practically free from deep pittings or pores, and larger and more rounded than that of the sonthern bird. The average long diameter is 6.15 inches and short diameter 5.35 inches and weight $3 \mathrm{lbs} .11 \mathrm{oz}$. (Pl. VII, fig. 3).

Found in Northern and Western Africa, and in times past ranged eastwards to Abyssinia, Arabia and South Palestine.

B. The Sonth African Ostrich, Struthio australis Gurney. Smaller than the North Africin, the less size being due to the slender and shorter legs and neck rather than to any difference in the size of the

\footnotetext{
1 The wild ostrich breeds when about four years old but the domesticated bird, largely as a result of high nutrition as a chick and young bird, along with a certain amount of unconscious selection, now usually breeds when between two and three years old, though chicks are sometimes hatehed from birds uuder two yaars.
} 


\section{Crossing the North and South African Ostrich}

body. The head extends about $7 \frac{1}{2}$ feet from the ground, the length from the tip of the beak to the end of the tail is $7 \frac{1}{2}$ feet, and the total weight about 240 lbs. The neck is about 3 feet long, and the body feathers pass upwards for about 1 foot; the knee joint is about $3 \frac{1}{2}$ feet from the ground; a claw is rarely present on the small toe, and the scales on the tarsus and third toe are usually continuous.

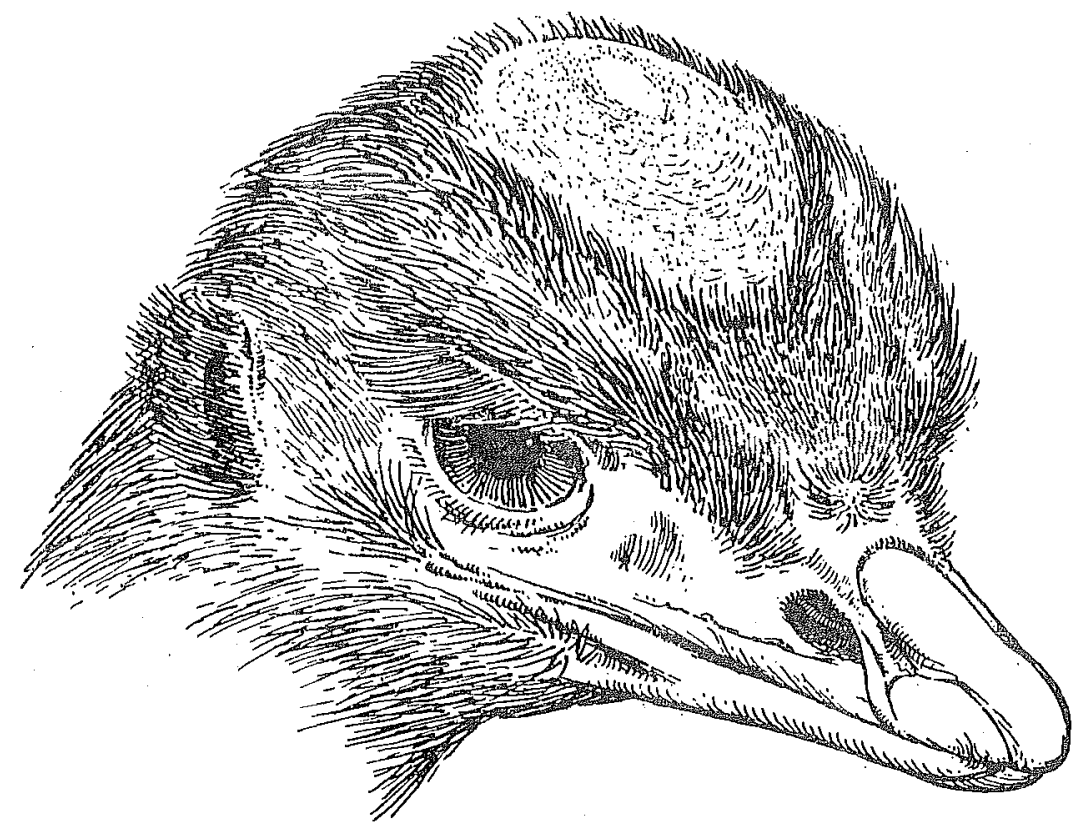

Text-fig. 1. Head of North Africen ostrich showing baldness. The oval area towards the hinder border represents the pineal spot.

The wing plumes average about 36 to each wing, but vary from 33 to 42 .

The skin of the neck, body and legs is pale yellow in chicks, dark grey in the mature hen, and dark blue in the cock. In the sexually ripe cock only the beak, front part of the head, naked skin round the eyes and tarsal scales are a bright scarlet, and the rest of the tarsus and toes pink, but the redness does not extend above the ankle.

The crown of the head is without any bald patch, and often bears a tuft of longer hair-like feathers in the middle.

The egg is deeply pitted all over, smaller and more oval than in the northern bird. The average long diameter is 6 inches and the short diameter 5 inches; the weight about $3 \frac{1}{2}$ lbs. (Pl. VII, fig. 3). 
Inhabits practically the whole of the sub-continent of Sonth Africa.

Observed alongside one another, as can now be done at Grootfontein, no one could fail to distinguish the northern from the southern ostrich. The greater height of the former, the stronger limbs and the light yellow of the skin are obvious features, while the sexually mature cock is still more distinctive on account of the brilliant scarlet of the head, neck and legs, and the red colour of the body generally. The naked patch on the head and the smooth, larger eggs are just as constant distinguishing features. Many small differences of feather structure occur, and are of much importance to the practical ostrich farmer. Hitherto all the distinguishing characters of the imported northern ostrich have been retained under the new conditions of South Africa and re-appear in the progeny, showing that they are hereditary and independent of climatic and other environmental influences.

Whether the northern and the southern ostrich are to be regarded as dislinct species depends largely upon one's conception of the term species and will be discussed later. It may be noted however that the two are found to interbreed freely and reciprocally, and the crosses or hybrids have also been proved to be fertile, both inter se and with either of the parent forms; at the same time the two races have many distinctive characters which are germinal in their origin.

\section{Nature of The Material.}

From a genetical point of view the material on which the investigations are being conducted is heterogeneous. The imported Nigerian birds are such as were procured by the Arabs from wild nests, and then reared in lrraals for the sale of their plumage. Methodical ostrich farming, as conducted in South Africa, is scarcely known in North Africa, and chicks are not bred in captivity; hence the birds are uninfluenced by any artificial selection. They exhibit much variation in the details of feather structure, and many distinct commercial types of plumes are represented, though all the birds come from one area. On importation the greater number were chicks about six months old. The majority of the older birds failed to become adapted to their new environmental conditions, and many died from lack of immunity to the various parasitic diseases affecting the southern bird. A selection has been made of those producing the most desirable plumage and the others discarded. 


\section{Crossing the North and South African Ostrich}

The South African birds employed are such as have been produced by gradual selection during the fifty years or so since ostrich farming was first established at the Cape. The foundation stocks naturally consisted of wild birds, and the best of these and their progeny have been employed in building up the superior strains of to-day. The ultimate object in ostrich breeding is simple and well defined. The farmer selects only for feather production; no other character of the bird is taken into account, as any weakness in constitution or breeding power is scarcely observable. Also, practically only one-feather ideal exists. namely, the largest feather combining all the many desirable features at their maximum. The technical "points" relate to details concerning length, width, strength, shapeliness, density and lustre, in all of which ostrich plumes vary greatly. None of the original Soutl African strains possessed the highest expression of these in combination, and the object throughout has been to gather into one all the best features available. As yet no breeder has succeeded in doing this, though many are nearing the desired end. The ostrich farmer clearly appreciates the distinctness of the various characters of the plume, though in his selection for mating he proceeds mainly on the assumption of a blending inheritance, and in practice the method is succeeding, even though progress is slow and much variety is encountered in the progeny. When the ideal type of plume has been built up it is understood that it must be "fixed " by a measure of in-breeding, and at present widely divergent crosses are rarely made.

It is generally conceded that, notwithstanding all the selection which has taken place, no advance has been made on the best of the feather points originally scattered among the foundation stocks, except such as can be ascribed to improved nutrition and other conditions dependent upon domestication ${ }^{1}$. Ail that the farmer has done is to combine in the one plume the best of the features originally distributed

1 As long projecting outgrowths of the epidermis, with a core or medulla of highly vascular nourishing dermis, ostrich plumes during their six montlis' grow th are remarkably sensitive to the nutritive and other physiological conditions of the bird; even the variations of blood-pressure between day and night often leave their impress upon the growing feather in the for'm of "bars," while climatic conditions may make or mar the success of the feather crop. The greatest difference in value obtains between a well-grown and an imperfectly grown crop of feathers, and this accounts for the great care bestowed upon the management of the birds, and the lighly stimulating food supplied. Probably the high grade ostrich is the best cared-for and most pampered of all our domestic animals. No better subject for studying the influence of a varying nutrition and blood-pressure upon a growing structure could be chosen than its long plumes, growing at the rate of a quarter of an inch a day. 
among the many wild strains; but it has been found. impossible to change any of the characteristics beyond what nature provided. Taking the features separately the ostrich plume affords a noteworthy instance of the impossibility of improvement, beyond the maxima originally present, by means of continued selective breeding. All that the process has achieved is to segregate the characters most desired; moreover, in connection with the points of the feather no hint of any sport or mutation ever occurs.

When comparing closely the many commercial varieties of ostrich plumes, each representing a separate type to the specialist and having a distinct value, the question arises as to how far the many differences in size, density, shape and hustre should be considered as fluctuating variations, or how far they are elementary characters. Farming experience has fully proved that selective breeding within a type will not change any of the minutiae of the type. If a farmer requires any particular feature added to his strain he must procnre it from birds whose plumage displays it; no degree of breeding will otherwise produce it. It is thus shown that the variations distinguishing the types are germinal, not environmental, and should therefore be regarded as representing definite elementary characters. Yethow many of these elementary characters must be represented in even a single ostrich plume! No cloubt the same multiplicity of small characters appeals to the specialist in an intensive study of any domesticated stock. Experimental investigations are usually undertaken on one or on only a few of the pronounced characters, but when all the many details have to be considered which are of the greatest importince to the practical breeder, there appears no limit to which analysis can be carried ${ }^{\mathrm{I}}$.

The present paper is confined to the behaviour in crosses of certain of the more prominent characters which distinguish the northern and southern ostrich, such as the dimensions, colour, the bald head patch and details connested with the egg, and others which the two have in common, such as the number of plumes on the wing, the scales on the middle toe and the claw on the fourth toe. An attempt is made to arrive at the germinal constitition of the ostrich so far as concerns these characters, as well as their adaptive value and manner of establishment in the race.

1 Two preliminary attempts have already been made to analyse the various plume characters of the parents and progeny in cruss-matings, Breeding Experiments with North African and South African Ostriches, I. "The Plumes of Parents and Chicks"; II. "The Plumes of the Second and Third Clippings," Local Series, Nos. 13 and 17, Department of Agriculture, Union of South Africa, 1917. 


\section{DIMENSIONS.}

On account of its restless nervous nature and the difficulty of fixing upon constant determinable points the live ostrich is not a creature which lends itself to accurate bodily measurements. In any troop it will be found that the members differ much among themselves, and the same individual varies at different ages and according to its nutritive condition. Hence the northern and southern birds and the crosses from them can be compared only in general terms, as when seen side by side. The average North Afican ostrich is a much taller bird than the South African, being longer in the legs and neck. The head reaches to a height of from eight to nine feet from the ground whereas in the Cape bird it extends only seven to eight feet. The feet, legs and neck of the Nigerian bird are also more robust. The general dimensions of the body do not differ much in the two, the greater size of the northern being mainly a result of the longer legs and neck. As a chick and young bird the body of the northern ostrich however tends to narrow behind more than the southern, but later this becomes a feature largely dependent upon the nutritive state. The relative sizes admit of the two being easily picked out in a mixed troop, the heads of the northern birds towering a foot or so above those of the southern.

The cross-bred birds at maturity stand higher than pure Cape birds, but are not so high as the Nigerian. As chicks the body tends to narrow behind more than in Cape chicks, so that, with the slightly longer legs and tapering body, they appear decidedly more slender than Cape chicks of the same age. On the whole it can be said that as regards size, especially length of limbs and neck, the hybrids follow neither one parent nor the other but are intermediate between the two, though the statement is not one which can be supported by actual measurements.

The two chicks of the second cross-bred generation already reared are now a year old and as regards their general size are strikingly like the South African grandparents as contrasted with the North African, including the shorter, less robust legs and neck. When mingling with first generation cross-breds of the same age the difference is most marked, and no one would hesitate in regarding. them as pure Cape birds. Such a result is at least suggestive that the distinctive sizes of the northern and southern ostrich will undergo segregation in the $F_{2}$ generation, but further chicks will be necessary before the real nature of the segregation can be determined. 


\section{Colour.}

The skin or body colours of the ostrich, as distinct from those of the plumage, vary from the chick to the adult stage, are different in the hen and the cock, and change in the latter with the breeding state. They also vary with the physiological condition of the bird, according as the surface of the skin is clean or covered with scurf. When low in condition the skin becomes dry and scaly; thereby masking the true colours; but as a higher physiological state is reached the scurf peels off or is preened off, and the true fresh colour is revealed. This is particularly the case at the beginning of the breeding season when the skin colours are at their brightest. The colour is readily seen on the naked legs and under the wings, around the eyes and beak, and elsewhere by turning aside the overlapping feathers. Chicks of Joth sexes are practically alike and even young birds show little distinction. The hen remains throughout of the same colour as young birds, but the cock undergoes a change beyond, and in places assumes a brilliant scarlet as the nuptial state is attained. From the chick onwards the colour distinctions between the North African and South African ostriches are strongly marked.

The red and scarlet colouration of the cocks of both races, as well as the rich dark blue of the Cape bird, are found to be dependent upon the presence of the testes, while the black plumage is dependent upon the absence of the ovaries. South African cocks which have been castrated while young never assume the red and scarlet skin colours, but retain the light or dark grey of all young birds and nnature hens. On the other hand the plumage of castrated cocks attains the normal blackness of the sex as contrasted with the greyness of the hens, from which it may be inferred that the formation of the black pigment of the feathers is not subject to any influence from the male gonads. Spayed hens retain their ordinary body colour but the normally grey feathers are found to assume the blackness of the cock, showing that ordinarily the secretions from the ovaries exercise an inhibitory influence on the formation of black pigment in the feathers of the hen, though having no action on the skin colour ${ }^{1}$.

1 Prof. T. H. Morgan, Amer. Nat. Vol. Lx. Sept. 1917, in the case of the cock bird of the Sebright bantam which is "hen-feathered," has proved experimentally that when castrated a complete change in the plumage occurs, normal cock feathers appearing. He considers that, as in the hen, some interñal secretion, acting through the gonad, must inhibit the development of the secondary sexual characters in the hen-feathered cocl. Morgan also refers to certain experiments by Goodale who has found that when the hen of 


\section{Crossing the North and South African Ostrich}

The secondary sexual colours of the skin and plumage of the ostrich are thus determined by altogether different influences; the full attainment of the one is dependent upon the presence of the testes and of the other upon the absence of the ovaries. Two North African birds at Grootfontein, although about six years old, have shown no signs of sexual maturity; they retain the cream yellow of all northern young birds and mature hens, but have the black plumage of cocks. Evidently some abnormality is connected with the internal gonads, but from the external appearance of the birds it is impossible to say whether they are cocks or hens. It may be noted that the removal of the ovaries or testes, especially after a bird has attained maturity, has little or no effect on certain of the sexual instincts. Thus a castrated hen will go through the characteristic snapping of the beak and fluttering of the wings as if broody, and will even crouch to receive the cock; while the castrated cock will perform his ordinary "rolling" display and even mount a crouching hen.

In determining the sexual colours of the male ostrich the testes clearly give rise to some secretion, presumably of an enzyme nature. This must be produced at first in small quantities, and the colour changes come slowly; but as the testes ripen and become functional more of the enzyme must be forthcoming, for the colom intensity increases and remains brilliant throughout the mating period. With the beginning of the six weeks' period of incubation the testes become less active, pairing ceases, less enzyme is produced and the colour fades. The differences between the sexual colours of the northern and southern bird are well defined, and must be germinal in the first instance; but the factors must act through the gonads, and presumably these exert their influence by means of specific enzymes. Even if we regard the germinal factor's as themselves enzymes, as Troland ${ }^{1}$ and others would have us do, those concerned with the sexual colours must express themselves through the gonads.

'Though the scarlet colour of the cock is a secondary sexual character' it may well be doubted whether it has any influence on the mating of the birds, or any preferential value in the eyes of the hen, as is so often

ordinary breeds of fowls is spayed she develops the full male plumage, as is also proved above for the lien ostrich. Seeing tliat the pluniage of the cock ostrich is more valuable than that of the ben the results from spaying the latter have an economic bearing and the practice is followed by some farmers.

1 Troland, L. T., "Biological Enigmas and the Theory of Enzyme Action," Amer. Nat. Vol, LI. June, 1917. 
supposed to be the case with the bright nuptial colours of birds. For northern cocks are a bright scarlet over all their exposed parts at the time of sexual ripeness while southern cocks are scarlet only over the head and the tarsus and are far less striking in their general appearance, yet a northern hen will crouch just as freely for the latter as for the former. Occasionally ostriches exhibit a dim suggestion of preferential mating, but in practice it is found that any hen will pair with any cock, and in "camping off" as breeders the farmer never takes into account any possible preferences on the part of the birds themselves. In a state of nature, on the open veld, a cock gathers round him one or more hens as the breeding season approaches, and very definite spatial limitations become established among the different breeding sets, and woe betide any cock which may wander on the area appropriated by another. In all this however the hens are purely passive and indifferent, and are prone to lay in the same nest, as many as 60 or 70 eggs being sometimes found in the one shallow depression. Further, as in most other birds; the plumage is at its highest state of development at the beginning of the mating season, as if still further adding to the attractiveness of the cock. Yet farmers as often as not clip the plumes before mating birds, and so preserve them from wear and tear, without however any influence on the readiness with which pairing takes place.

The Northern Ostrich. In North African chicks the skin is a bright deep yellow, almost orange, over the legs and head, and a slightly paler yellow over the body and neck. As maturity is reached the hen becomes a light yellow, the tarsal scales assuming a light or dark horny brown. Some northern hens are slightly pink over parts of the body, and the colour may show through the white downy covering of the neck.

The North African cock nndergoes remarkable colour changes as sexual maturity is attained, which are a sure guide to the farmer as to the breeding condition of the bird. The deep yellow of the chick is gradually replaced by a light yellow, this by pink, and then by red, reaching a bright scarlet over the legs, body, neck and head as the actual mating period is reached. The bright scarlet colour contrasts strongly with the jet black body-feathers, white waving wings, erect light brown tail feathers and fleecy white down of the neck, and makes of him a glorious creature as he prances about in his breeding camp in all the pride and pugnacity of his sex. The nuptial colours pale greatly when nesting begins, and also when the breeding season is over, the body being reduced to a pale pink or brick colour. At its height so 


\section{Crossing the North and South African Ostrich}

sensitive is the colour to the physiological state of the bird that close observation often reveals variations in the intensity within the same day, as well as from day to day.

The Southern Ostrich. The skin of South African chicks is at first pale yellow in colour and afterwards dark grey. Highly fed Cape chicks may show a rich deep yellow round the eyes and beak, though this does not continue for more than a few months. Mature southern hens are a dark grey over the legs, body, neck and tarsal scales.

The Cape cock is at first a dark grey or steel colour, much like the hen, but as sexual maturity is gained he assumes a fresh, bright blue over the greater part of the body, while the tarsal scales, beak and naked parts round the eyes become a bright scarlet; the small scales over the sides and hind part of the tarsus may also be red or pink, but ordinarily none of the red colouration extends beyond the tarsus, nor over the body and neck.

Thus northern chicks are a deeper yellow than southern chicks. They pass to a pale yellow and the hen remains at this stage, but the cock passes beyond to a pink and then a scarlet stage. The pale yellow of southern chicks is early replaced by a dark grey which persists in the hen, but is followed in the cock by a blue or blue grey as sexual maturity is reached; moreover, only the tarsal scales, beak, and skin round the eyes assume the bright scarlet which characterises practically the entire body of the northern bird.

In southern cocks the red colour of the northern would appear to be latent, or perhaps wholly obscured by the dark blue; for on recovering from an injury to the neck or body it is often found that the scar of the new skin shows a reddish tinge.

Cross-bred Ostriches. The colour of the skin of cross-bred chicks is intermediate between that of northern and southern chicks. The legs, body and large scales are a pale yellow, which is lighter than that of Cape chicks but never so deep as that of Nigerian chicks. The adult cross-bred hen retains the light yellow body colour, though usually it becomes a little darker compared with the chick. The colour remains darker than that of the pure northern hen, but is invariably lighter than the pure Cape.

The cross-bred cock retains the uniform light yellow of the hen until sexual maturity approaches. He then assumes a pink tinge in places and later the bright scarlet. As noted, however, it is in the 
extent of the red colouration, not in its intensity, that the northern and southern cocks differ so conspicuously; in the former it is diffused practically all over, while in the latter it is limited to the head and legs below the ankle joint. The sexually mature cross-bred cock is decidedly intermediate between these two as regards the area of the body assuming the red colour. The head and tarsus are scarlet as in both parents, but only a slight pink colour appears on the upper part of the leg and also over the neck, and may even tinge the other parts of the body, though without approaching the bright red of the northern parent. The various cross-bred cocks naturally differ as regards the degree and extent of the colouration, but they never wholly follow one parent or the other. In extreme cases the body colour may be a grey blue almost like the southern cock or a grey yellow nearly like the northern, but all kinds of intermediate tints are to be met with, even in birds from the same nest.

In all the cross-bred cocks the red of the neck is displayed to a greater or less degree through the white downy covering. Sometimes it is only apparent when the small hairy feathers are turned aside and the loose skin put on the stretch. It then appears as red showing through a bluish ground, the two producing a purple. From this it would seem as if both the blue of the southern bird and the red of the northern were represented, the resultant purple being the product of the two. It is evident that the degree of redness of the body and neck is partly dependent upon the other body colours. If the latter is dark blue it naturally tends to obscure the red, while if the body colour is only a pale yellow the red becomes more obvious. The nuptial colours, dependent upon the presence of the testes, are superimposed upon the true body colours.

As regards the two $F_{2}$ chicks the colour of the body, legs and neck is quite as dark as that of any Cape hen, showing no influence from the lighter colour of the northern grandparent and the intermediate light colour of the cross-bred parents. Both being hens however the colour is not so distinctive as it would be in the case of cocks. Taken as a preliminary result it certainly suggests that the colours of the northern and southern birds have a separate factorial basis, and that segregation will take place in the second cross-bred generation. The rearing of further $F_{2}$ chicks will be awaited with interest as likely to solve the problem. 


\section{Bald Head Patch.}

The crown of the head of the South African ostrich is covered with short, hair-like feathers, which often form a tuft of longer hairs in the middle. A bare pineal spot ${ }^{1}$, present in all ostriches at the back of the head, is so small in the adult as to be only noticeable when the fenthers are turned aside. The North African ostrich on the other hand is distinguished by having the top of the head for the most part naked, a bald patch beginning at the back and extending forwards in a shieldlike fashion between the eyes (Text-fig. 1, p. 158). The area is roughly pear-shaped, but may be partly divided down the middle. In diagnostic descriptions the baldness is considered to be a character of some importance in separating the northern species from the southern and is even mentioned in the writings of Pliny ${ }^{2}$.

The extent and shape of the naked space vary a little in different ostriches, but all the North African birds at Grootfontein display it to a greater or less degree. It is quite independent of the pineal spot, and its posterior border may either include this (Text-fig. 1) or pass in front of it. In some birds, instead of forming a continuous patch, it is divided more or less down the middle, having then a decided bilaterality. Often a tuft of long, hair-like feathers remains towards the middle of the hinder border, corresponding with the tuft in the southern bird, and gradually disappears forwards. The area is covered with a horny, scurfy layer, which peels off at times, exposing a fresh, clean surface of the skin with the hard bony skull immediately below.

The baldness is not apparent in the North African ostrich .chick when first hatched. At that time the head is covered with short bristly down as in the South African, and the character becomes established in the course of the first six months or so of growth. It is gradually formed by the dropping out of the hairy feathers from about two months onwards, and in a batch of chicks of the same age practically all stages in the loss can be observed, the feathers to remain longest being those of the middle tuft. No sharp line of separation occurs between the naked and the covered part of the head; a few stunted feathers represent

1 An extra-cranial pineal body has lately been discovered in the ostrich. At a certain stage of development it shows as a black pigmented area or vesiole which later disappears, and only a dark, oval area, devoid of feathers remains in the nowly hatehed ehick and persists throughout life. Apparently the ostrich is the only bird with stach a well-defined pineal body, recalling that of the reptilia and persisting as a pineal spot.

2 Hist. Mund. lib. xr. cap. xxxvm. 
the gradual transition, while the medium tuft may or may not persist. No corresponding falling out of the feathers ever takes place in the Cape chick.

Naturally some interest has been attached to the behaviour of the bald patch in the crosses of the northern and southern ostrich. Of the hundred or so cross-bred chicks which have been hatched none at first showed any signs of baldness, but in every case the feathers began to fall out when the chick was two or three months old, and at six months the patch was established as completely as in adult North African ostriches. Thus the baldness of the northern bird is shown to be dominant over its absence in the southern bird.

The two second generation chicks already reared are now well over the age at which the bald patch becomes established, and in one of them the head remains covered with hairy feathers as in southern birds while in the other the baldness has been formed as distinctly as in any northern bird. The $F_{2}$ chicks thus afford evidence that factorial segregation takes place in the second hybrid generation, and there can be little question that when sufficient chicks of this generation have been obtained it will be found that baldness behaves as a homozygous dominant in strictly Mendelian proportions.

The bald head patch is therefore a distinctive Mendelian unitcharacter separating the northern and the southern ostrich. The differences associated with the dimensions and colours of the birds, and also those of the egg, are differences of features common to both, but in the Cape bird there is nothing suggestive of the baldness of the Nigerian. It is an entirely new character which has appeared in the latter race of ostriches, but not in the former. It may be regarded as a mutation, and was presumably fully developed from the beginning, for though it varies somewhat in its extent and form the differences are no more than can be regarded as fluctuating variations. That it is germinal in its origin is manifest since it appears in all chicks, both pure and cross-bred, while its dominause in all the latter proves that the parents are duplex or homozygous with regard to it.

'It can hardly be supposed that the baldness has arisen in response to any external influence, for it is unlikely that anything environmental could affect the top of the head of the northern bird which would not have a corresponding action upon its southern relative, even if it were possible that any influencing of the kind could bring about a corresponding change in the germ plasm. Nor can it be deemed to have any adaptive value. It lends strong support to the view rnaintained by 
Bateson, and also by Morgan, that new characters make their appearance as a result of changes in the germ plasm, without any reference to external influences, or any utilitarian value or need of the individual. Since the baldness is now present as a duplex dominant in all the imported birds it must have originated long ago in the history of the northern ostrich, sufficiently long for the change to have affected all the individuals. 'For, as will be shown later, there is good reason to suppose that in the ostrich a new character appears at first in only a few members, but gradually extends to more and more, by the continued change de novo in the germ plasm of the nulliplex members of the race.

\section{The EgG.}

As in all other birds the eggs from the same ostrich and also from different ostriches vary within certain limits, as regards size, shape and surface characters. Beyond these fluctuating variations however certain well-defined differences distinguish the egg of the North African from that of the South African bird (Pl. VII, fig. 3).

Egg of North African Ostrich. The egg of the northern bird is practically always larger than that of the southern, the shell is almost free from obvious pores or pittings, and presents an ivory-like smooth surface. Usually also the northern egg is rounder in shape or less oval. Measurements have been taken at the nest of the long and short diameters of four series of eggs and are as follows, in inches:

TABLE I.

Measurements of Eggs of North African Ostrich.

\begin{tabular}{|c|c|c|c|c|c|}
\hline & \multicolumn{2}{|c|}{ Series A } & & \multicolumn{2}{|c|}{ Series B } \\
\hline & $\begin{array}{c}\text { Long } \\
\text { Dinmeter }\end{array}$ & $\begin{array}{c}\text { Short } \\
\text { Dịmeter }\end{array}$ & & $\begin{array}{c}\text { Long } \\
\text { Dinmeter }\end{array}$ & $\begin{array}{c}\text { Short } \\
\text { Diameter }\end{array}$ \\
\hline 1 & 6.00 & $5 \cdot 19$ & 1 & $6 \cdot 12$ & $5 \cdot \tilde{0} 0$ \\
\hline 2 & 5.94 & $5 \cdot 19$ & 2 & 6.50 & $5 \cdot 50$ \\
\hline 3 & 6.00 & $5 \cdot 25$ & 3 & $6 \cdot 12$ & $5 \cdot 38$ \\
\hline 4 & $6 \cdot 12$ & $5 \cdot 31$ & 4 & 6.38 & $5 \cdot 25$ \\
\hline 5 & $6 \cdot 19$ & $5 \cdot 31$ & 5 & $6 \cdot 12$ & $5 \cdot 25$ \\
\hline 6 & $6 \cdot 19$ & $5 \cdot 31$ & 6 & $6 \cdot 25$ & $5 \cdot 38$ \\
\hline 7 & $6 \cdot 12$ & $5 \cdot 31$ & 7 & $6 \cdot 38$ & $5 \cdot 25$ \\
\hline 8 & $6 \cdot 00$ & $5 \cdot 25$ & 8 & $6 \cdot 25$ & $5 \cdot 38$ \\
\hline 9 & $6 \cdot 00$ & $5 \cdot 25$ & 9 & $6 \cdot 00$ & $5 \cdot 50$ \\
\hline 10 & $6 \cdot 00$ & $5 \cdot 19$ & 10 & $6 \cdot 25$ & $5 \cdot 50$ \\
\hline 11 & $5 \cdot 94$ & $5 \cdot 19$ & 11 & $6 \cdot 25$ & $5 \cdot 38$ \\
\hline rage & $6 \cdot 05$ & $5 \cdot 25$ & & $6 \cdot 24$ & $5 \cdot 48$ \\
\hline
\end{tabular}


TABLE I-continued.

\begin{tabular}{|c|c|c|}
\hline & \multicolumn{2}{|c|}{ Series $\mathrm{C}$} \\
\hline & $\begin{array}{l}\text { Long } \\
\text { Diamoter }\end{array}$ & $\begin{array}{l}\text { Short } \\
\text { Diameter }\end{array}$ \\
\hline 1 & 6.25 & $5 \cdot 38$ \\
\hline 2 & 6.25 & $5 \cdot 31$ \\
\hline 3 & $5 \cdot 94$ & $5 \cdot 12$ \\
\hline 4 & 6.00 & $5 \cdot 19$ \\
\hline 5 & $6 \cdot 12$ & $5 \cdot 44$ \\
\hline 6 & $6 \cdot 25$ & 5.50 \\
\hline 7 & $6 \cdot 25$ & $5 \cdot 38$ \\
\hline 8 & 6.06 & $5 \cdot 25$ \\
\hline 9 & 6.12 & $5 \cdot 38$ \\
\hline 10 & $6 \cdot 25$ & $5 \cdot 44$ \\
\hline 11 & 6.00 & $5 \cdot 19$ \\
\hline 12 & $6 \cdot 12$ & $\tilde{5} \cdot 38$ \\
\hline 13 & 6.06 & $5 \cdot 31$ \\
\hline 14 & $6 \cdot 25$ & 5.50 \\
\hline rage & $6 \cdot 14$ & $5 \cdot 34$ \\
\hline
\end{tabular}

\begin{tabular}{|c|c|c|}
\hline & \multicolumn{2}{|c|}{ Series D } \\
\hline & $\begin{array}{c}\text { Long } \\
\text { Dinmeter }\end{array}$ & Diameter \\
\hline 1 & $6 \cdot 06$ & $5 \cdot 38$ \\
\hline 2 & $6 \cdot 31$ & $5 \cdot 38$ \\
\hline 3 & $6 \cdot 25$ & 5.38 \\
\hline 4 & $6 \cdot 06$ & $5 \cdot 44$ \\
\hline 5 & $6 \cdot 12$ & $5 \cdot 31$ \\
\hline 6 & $6 \cdot 25$ & $5 \cdot 31$ \\
\hline 7 & $6 \cdot 25$ & $5 \cdot 38$ \\
\hline gge & $6 \cdot 19$ & $5 \cdot 37$ \\
\hline
\end{tabular}

Thus the average long diameter of 43 northem eggs is 6.15 inches and the short diameter $5 \cdot 35$ inches, representing an average difference between the lwo axes of 0.8 inch.

Egg of South African Ostrich. The egg of the southern bird is deeply pitted all over the surface, and pits often larger and more plentiful at the air-chamber end, hence the shell does not present the ivory smoothness of the northern egg. A Cape hen will sometimes produce a nearly smooth, round egg, but never to so marked a degree as the typical Nigerian hen. Also the latter may occasionally lay eggs with deeper pittings than usual, especially in the first one of the season. Among a number of eggs from northern and southern birds mixed together no mistake can however be made in separating the one type from the other.

The pitting which gives such a marked character to the southern egg is associated with the respiratory pores of the shell. In the northern shell the pores are so small and open so close to the surface as to be scarcely visible to the naked eye, and are mostly scattered singly with but little grouping. Hence the surface appears almost uniformly smooth, though fine pores can be detected with a lens. In the southern egg the shell pores are larger, sunken below the general surface and mostly in small groups, varying from about six to twelve in a group. It is the close grouping of the sunken pores which gives rise to the pitted surface. In eggs which have been in the nest for some time dirt tends to accumulate within the pits and thns accentuates their presence, whereas in the northern egg the pores are too small and shallow. In both types the 
outer enamel layer shows differences in thickness and with it the polished character of the surface. All the eggs are a cream or yellow colour when freshly laid but fade considerably on exposure.

Measurements have been taken of 20 eggs as follows :

TABLE II.

Measurements of Eggs of South Afriean Ostrich.

\begin{tabular}{|c|c|c|c|c|c|}
\hline & \multicolumn{2}{|c|}{ Series A } & & \multicolumn{2}{|c|}{ Series B } \\
\hline & $\begin{array}{c}\text { Loug } \\
\text { Diameter }\end{array}$ & $\begin{array}{c}\text { Short } \\
\text { Diameter }\end{array}$ & & $\begin{array}{c}\text { Long } \\
\text { Diameter }\end{array}$ & $\begin{array}{c}\text { Short } \\
\text { Diameter }\end{array}$ \\
\hline 1 & $6 \cdot 00$ & $4 \cdot 62$ & 1 & $6 \cdot 25$ & $5 \cdot 12$ \\
\hline 2 & $5 \cdot 69$ & $4 \cdot 81$ & 2 & $5 \cdot 81$ & $4 \cdot 88$ \\
\hline $\mathbf{3}$ & $6 \cdot 00$ & $5 \cdot 12$ & 3 & $5 \cdot 75$ & $4 \cdot 94$ \\
\hline 4 & $5 \cdot 62$ & 4.88 & 4 & $5 \cdot 94$ & 5.06 \\
\hline 5 & 6.25 & 4.81 & 5 & $6 \cdot 00$ & $5 \cdot 00$ \\
\hline 6 & $5 \cdot 69$ & $4 \cdot 50$ & 6 & $5 \cdot 81$ & $5 \cdot 00$ \\
\hline 7 & $6 \cdot 12$ & 4.81 & 7 & 6.00 & $5 \cdot 00$ \\
\hline 8 & $5 \cdot 81$ & $5 \cdot 00$ & 8 & $5: 88$ & $5 \cdot 00$ \\
\hline 9 & $6 \cdot 06$ & $5 \cdot 00$ & 9 & 6.00 & $5 \cdot 00$ \\
\hline 10 & 6.00 & $5 \cdot 00$ & 10 & $5 \cdot 94$ & 5.06 \\
\hline erage & $5 \cdot 92$ & $4 \cdot 85$ & & $5 \cdot 93$ & $5 \cdot 00$ \\
\hline
\end{tabular}

Thus the average long diameter is $5 \cdot 92$ inches and the short diameter 4.92 giving a difference of 1 inch. With such variable structures as eggs a larger series of measurements is desirable in order to secure a more reliable comparison. They serve to show however that on the average the northern egg is about a quarter of an inch longer $(6.15-5.92=0.23$ inch) and two-fifths of an inch broader than the southern egg $(5.35-4.92=0.43)$. The mean clifference in the two diameters is 0.8 inch for the northern and 1 inch for the southern, indicating that the former are rounder or less oval than the latter.

Ligs from Cross-matings. In breeding for cross-bred chicks the eggs follow the characteristics of the hen whatever the cock may be, that is, the eggs laid by a northern hen mated with a southern cock are large, round and unpitted, while those from a southern hen mated with a northern cock are smaller, oval and pitted. Thus as regards size, shape and surface features, the egg as laid is uninfluenced by the male bird and partakes wholly of the nature of the hen. This is what would ordinarily be expected, seeing that the germ from the cock unites only with the germ of the hen, and scarcely any further change takes place before the egg is laid. As the albumen, shell-membranes and shell are formed in the oviduct of the hen after fertilisation it is difficult to see how the coverings of the egg could be influenced. Instances are adduced however where in crosses of other birds giving differently coloured eggs 
the cock seems to exercise some influence, the phenomenon being spoken of as Xenia (Journ. Heredity, Vol. vi. No. 5). The diverse characters of the eggs of the northern and southern ostrich afford a good test case of the possibility of Xenia occurring, but from none of the cross-matings has any indication of the phenomenon been forthcoming.

Eggs from Cross-bred Hens. In cross-bred hens are naturally combined the possibilities of both the northern and the southern parents, and the characters of the eggs laid by them are just as mucli a part of the make-up of the bird as are the more obvious body features. The question therefore arises whether the eggs laid by cross-bred hens will follow those of one parent or the other, or be something intermediate between the two. Scores of eggs laid by cross-bred hens have been examined at the nest and in the incubator and in all cases have been found to be

TABIE III.

Measurements of Eggs of Cross-bred Ostriches.

\begin{tabular}{|c|c|c|c|c|c|}
\hline & Seri & A & & Seri & es B \\
\hline & $\begin{array}{l}\text { Long } \\
\text { Díneter }\end{array}$ & $\begin{array}{l}\text { Short } \\
\text { Dinmeter }\end{array}$ & & $\begin{array}{l}\text { Long } \\
\text { Diameter }\end{array}$ & $\begin{array}{c}\text { Short } \\
\text { Dirmeter }\end{array}$ \\
\hline $\begin{array}{r}1 \\
2 \\
3 \\
4 \\
5 \\
6 \\
7 \\
8 \\
9 \\
10\end{array}$ & $\begin{array}{l}6 \cdot 19 \\
6 \cdot 25 \\
6 \cdot 12 \\
6 \cdot 12 \\
6 \cdot 12 \\
6 \cdot 12 \\
6 \cdot 06 \\
6 \cdot 00 \\
5 \cdot 88 \\
5 \cdot 94\end{array}$ & $\begin{array}{l}5 \cdot 12 \\
5 \cdot 12 \\
5 \cdot 19 \\
5 \cdot 06 \\
5 \cdot 12 \\
5 \cdot 06 \\
5 \cdot 12 \\
5 \cdot 00 \\
5 \cdot 00 \\
5 \cdot 00\end{array}$ & $\begin{array}{r}1 \\
2 \\
3 \\
4 \\
5 \\
6 \\
7 \\
8 \\
9 \\
10\end{array}$ & $\begin{array}{l}6 \cdot 25 \\
5 \cdot 81 \\
5 \cdot 94 \\
6 \cdot 00 \\
6 \cdot 19 \\
5 \cdot 88 \\
6 \cdot 25 \\
6 \cdot 19 \\
6 \cdot 19 \\
5 \cdot 88\end{array}$ & $\begin{array}{l}5 \cdot 12 \\
4 \cdot 94 \\
4 \cdot 94 \\
5 \cdot 00 \\
5 \cdot 12 \\
4 \cdot 94 \\
5 \cdot 12 \\
5 \cdot 06 \\
5 \cdot 06 \\
5 \cdot 00\end{array}$ \\
\hline A verßge & 6.08 & $5 \cdot 08$ & & 6.06 & $5 \cdot 02$ \\
\hline & & & ies $C$ & & \\
\hline & & Long Diameter & & Short Diameter & \\
\hline & $\begin{array}{r}1 \\
2 \\
3 \\
4 \\
5 \\
6 \\
7 \\
8 \\
9 \\
10 \\
11 \\
12 \\
13 \\
14\end{array}$ & $\begin{array}{l}5 \cdot 94 \\
5 \cdot 81 \\
5 \cdot 88 \\
5 \cdot 75 \\
6.00 \\
6.06 \\
5 \cdot 62 \\
5 \cdot 94 \\
5 \cdot 88 \\
5 \cdot 88 \\
5 \cdot 81 \\
5 \cdot 88 \\
6 \cdot 06 \\
5.94\end{array}$ & & $\begin{array}{l}5 \cdot 12 \\
5 \cdot 12 \\
5 \cdot 12 \\
5 \cdot 06 \\
5 \cdot 12 \\
5 \cdot 06 \\
5 \cdot 12 \\
5 \cdot 12 \\
5 \cdot 06 \\
5 \cdot 12 \\
5 \cdot 12 \\
5 \cdot 00 \\
5 \cdot 12 \\
5 \cdot 12\end{array}$ & \\
\hline & & $5 \cdot 89$ & & $5 \cdot 09$ & \\
\hline
\end{tabular}




\section{4}

\section{Crossing the North and South African Ostrich}

intermediate as regards size, shape and the nature of the shell between typical northern and sonthern eggs. Obvious pittings occur over the shell, often more numerous towards the air-chamber end, but are never so plentiful nor so deep as in the eggs from the southern bird. The egg has neither the full size nor the roundness of the northern ostrich, but is larger than the southern, and its general surface is more enamel-like. Naturally variations occur in the eggs laid by different hens, and sometimes they approach those of the one parent more nearly and sometimes those of the other. The degree of pitting and smoothness of the surface of the shell do not admit of more than a general statement, but the dimensions of 34 cross-bred eggs are available for comparison with those of the northern and the southern eggs.

The average long diameter of 34 cross-bred eggs is therefore 6.01 inches and sliort diameter $5 \cdot 06$ inches, the difference between the two diameters being 0.95 .

The measurements of the three series may be compared as follows:

$\begin{array}{llccc} & & \begin{array}{c}\text { Long } \\ \text { Diameter }\end{array} & \begin{array}{c}\text { Short } \\ \text { Diameter }\end{array} & \text { Difference } \\ 43 \text { North African Eggs } & \ldots & 6 \cdot 15 & 5.35 & 0.80 \\ \text { 34 Cross-bred Eggs ... } & \ldots & 6.01 & 5.06 & 0.95 \\ \text { 20 South African Eggs } & \ldots & 5.92 & 4.92 & 1.00\end{array}$

Though not elaborate enough for many purposes the results suffice to indicate that as regards size and shape the cross-bred eggs are intermediate between those of the northern and the southern bird. They apparently ipproach somewhat nearer to the southern than the northern, but with such variable objects as eggs an indication of this kind may be deemed of little value when only small numbers are available.

The intermediate nature of the cross-bred eggs, as regards size, shape and the nature of the surface, may be taken to suggest that the different characteristics of the eggs of the two races of ostrich are dependent upon separate factorial representation in the germ plasm, as in the case of the dimensions and colours of the birds. Also the factors are not alternatives, for in the hybrid egg no one character of the parents is doninant or recessive to the other, but each strives, as it were, for expression, the result being something midway between the two.

\section{The WING Quills.}

In farming practice the number of plumes to the wing of the ostrich is an important matter, though selective breeding has hitherto been concerned with the quality of the plumes rather than with their quantity, it having been assumed that not much variation in number occurs. The 
first row of plumes, the wing quills or remiges, includes the familiar white plumes of the ostrich which are by far the most valuable as compared with the first and second rows of upper-coverts which are also clipped, and are black in the cock and grey in the hen. As the coverts alternate with the wing quills the numbers in all the rows are definitely correlated, so that for purposes of comparison among different birds attention can be confined to the first row, the remiges (Pl. VII, figs. 1 and 2).

North African Ostriches. The first-row feathers on each wing have been counted on 25 of the original imported North African birds and the results are given below. It will be noted that a difference of one or two plumes is often found between one wing and the other; but the cocks and hens show no distinction. The number on the wing varies from 33 to 39 , the arithmetical mean of the series being 36.54 ; represented graphically they approximate to a normal frequency curve with the mode at 36. Manifestly the birds represent a mixed population, a result of indiscriminate breeding in a race in which the numbers differ by small amounts; but indications are not wanting that a pure line can be built up of each number. We may regard each bird as heterozygous with regard to number of plumes, and a mixture of the kind given below is what would be expected seeing that the birds come from a single area in North Africa where no farming selection is practised.

TABLE IV.

First-row Plumes on Wings of Imported North African Ostriches.

\begin{tabular}{|c|c|c|c|c|c|c|c|}
\hline & & $\begin{array}{l}\text { Rigbt } \\
\text { Wing }\end{array}$ & $\begin{array}{l}\text { Left } \\
\text { Wing }\end{array}$ & & & $\begin{array}{l}\text { Right } \\
\text { Wing }\end{array}$ & $\begin{array}{l}\text { Left } \\
\text { Wing }\end{array}$ \\
\hline 1 & Hen, No. 11 & 39 & 38 & 14 & Hen, No. 87 & 36 & 37 \\
\hline 2 & Hen, No. 20 & 37 & 37 & 15 & Cock, No. 92 & 37 & 36 \\
\hline $3^{\circ}$ & Hen, No. 40 & 36 & 37 & 16 & Hen, No. 105 & 36 & 37 \\
\hline 4 & Hen, No. 41 & 34 & 35 & 17 & Hen, No. 108 & 37 & 36 \\
\hline 5 & Hen, No. 45 & 36 & 36 & 18 & Cook, No. 115 & 38 & 38 \\
\hline 6 & Coolk, No. 50 & 36 & 37 & 19 & Hen, No. 116 & 33 & 34 \\
\hline 7 & Hen, No, 63 & 37 & 38 & 20 & Hen, No. 130 & 35 & 36 \\
\hline 8 & Hen, No. 69 & 38 & 39 & 21 & Cook, No. 141 & 35 & 34 \\
\hline 9 & Hen, No. 71 & 36 & 35 & 22 & Gook, No. 252 & 38 & 39 \\
\hline 10 & Hen, No. 75 & 37 & 36 & 23 & Hen, No. 277 & 35 & 36 \\
\hline 11 & Cook, No. 78 & 37 & 36 & 24 & Cook, No. 284 & 36 & 37 \\
\hline 12 & Cocks, No. 84 & 35 & 36 & 25 & Hen, No. 287 & 38 & 39 \\
\hline 13 & Cock, No. 85 & 38 & 38 & & & & \\
\hline
\end{tabular}

The number of plumes on the wings of 15 pure North African chicks reared at Grootfontein from the importation, are also represented and give approximately the same arithmetical mean as the above, namely 36.7 , though without the low numbers 33 and 34 . The chicks are from 
three separate breeding sets and may represent some slight selective influence compared with the mixed importation.

TABLE V.

First-row Plumes on North African Ostrich Chicks reared at Grootfontein.

\begin{tabular}{llcc|rccc} 
& & $\begin{array}{c}\text { Right } \\
\text { Wing }\end{array}$ & $\begin{array}{c}\text { Left } \\
\text { Wing }\end{array}$ & & & $\begin{array}{c}\text { Right } \\
\text { Wing }\end{array}$ & $\begin{array}{c}\text { Left } \\
\text { Wing }\end{array}$ \\
$\mathbf{1}$ & No. 333 & $\mathbf{3 6}$ & $\mathbf{3 6}$ & 9 & No. 6 & 36 & 37 \\
2 & No. 334 & 36 & 37 & 10 & No. 7 & 39 & 38 \\
3 & No. 335 & $\mathbf{3 7}$ & $\mathbf{3 7}$ & 11 & No. 8 & 38 & 37 \\
4 & No. 1 & 37 & 37 & 12 & No. 9 & 35 & 36 \\
5 & No. 2 & 38 & 38 & 13 & No. 10 & 38 & 37 \\
6 & No. 3 & 36 & 36 & 14 & No. 11 & 36 & 38 \\
7 & No. 4 & 36 & $\mathbf{3 6}$ & 15 & No. 12 & 36 & 35 \\
8 & No.5 & 36 & $\mathbf{3 6}$ & & & &
\end{tabular}

South African Ostriches. In order to ascertain the number of plumes on the South African ostrich for comparison with the North African recourse has been had to the troops on various ostrich farms. Included among them are representatives from the best and most widely known ostrich strains of South Africa. It is only necessary to give the detailed countings of one series of 48 birds as an example, the average for the others agreeing closely. As much interchange of birds and chicks has taken place since ostrich farming commenced it is most unlikely that any additions to the series will vary from the averages here given.

TABIE VI.

Number of' Plumes on South African. Ostrichess. Farmers' Series. No. 4.

\begin{tabular}{|c|c|c|c|c|c|c|}
\hline & $\begin{array}{l}\text { Right } \\
\text { Wfog }\end{array}$ & $\begin{array}{c}\text { Left } \\
\text { Wing }\end{array}$ & & & $\begin{array}{l}\text { Right } \\
\text { Wing }\end{array}$ & $\begin{array}{l}\text { Left } \\
\text { Wing }\end{array}$ \\
\hline 1 Hen & 39 & 39 & 26 & Cock & 39 & 39 \\
\hline 2 Cocks & 35 & 35 & 27 & Cock & 36 & 35 \\
\hline 4 Cock & 37 & 36 & 29 & Cock & 39 & 39 \\
\hline 5 Cock & 36 & 37 & 30 & Cock & 38 & 38 \\
\hline 6 Hen & 36 & 36 & 31 & Hen & 37 & 34 \\
\hline 7 Cock & 37 & 36 & 32 & Hen & 37 & 38 \\
\hline 8 Hen & 37 & 36 & 33 & Hen & 36 & 35 \\
\hline 9 Cock & 37 & 38 & 34 & Hen & 36 & 37 \\
\hline 10 Cock & 36 & 36 & 35 & Cock & 36 & 36 \\
\hline 11 Cock & 36 & 35 & 36 & Cock & 36 & 35 \\
\hline 12 Cock & 37 & 37 & 37 & Cock & 35 & 36 \\
\hline 13 Hen & 39 & 38 & 38 & Hen & 35 & 35 \\
\hline 14 Cock & 36 & 36 & 39 & Hen & 37 & 38 \\
\hline 15 Cock & 38 & 38 & 40 & Cock & 36 & 35 \\
\hline 16 Hen & 36 & 36 & 41 & Gock & 39 & 38 \\
\hline 17 Cock & 38 & 37 & 42 & Gock & 39 & 38 \\
\hline 18 Cock & 36 & 37 & 43 & Cook & 40 & 39 \\
\hline 19 Cock & 37 & 36 & 44 & Cock & 35 & 34 \\
\hline 20 Gock & 38 & 37 & 45 & Hen & 37 & 38 \\
\hline 21 Clock & 39 & 38 & 46 & Gock & 36 & 36 \\
\hline Hen & 34 & 34 & 47 & Hen & 37 & 36 \\
\hline Hen & 38 & 38 & 48 & Hen & 37 & 36 \\
\hline 24 Hen & 37 & 36 & 49 & Cock & 37 & 37 \\
\hline 25 Coolx & 39 & 40 & 50 & Cook & 39 & 38 \\
\hline
\end{tabular}


The arithmetical means of five Farmers' Series are as follows:

\begin{tabular}{lll} 
No. 1 & $\mathbf{2 5}$ birds & $\mathbf{3 6} \cdot 88$ \\
No. 2 & 24 birds & $\mathbf{3 6} \cdot 58$ \\
No. 3 & 19 birds & $\mathbf{3 6} \cdot 97$ \\
No. 4 & 48 birds & $\mathbf{3 6} 87$ \\
No. 5 & 19 birds & $\mathbf{3 6 \cdot 6 3}$ \\
\hline
\end{tabular}

The average number of plumes on the South African ostrich is therefore the same as that on the North African, an important conclusion which could not have been arrived at without the opportunity of counting large numbers of each.

As the northern ostriches now at Grootfontein were all procured originally by the Arabs of Nigeria as chicks from wild nests, and are uninfluenced by any artificial breeding, we may presume that their plumes represent the average for the North African wild bird, and we have therefore good reason for concluding that the ostriches over the whole cuntinent of Africa produce the. same average number. From this it follows that during the fifty years of ostrich farming in South Africa no advance has been made on the number of plumes originally present on the wild bird. On the average the domesticated birds of to-day produce the same quantity of plumes as the original birds with which the first ostrich farmers commenced in the sixties.

Though somewhat remarkable at first sight this result is scarcely to be wondered at if we bear in mind the principles underlying ostrich breeding: Farmers have bred for quality; quantity has never been taken into account. Great advances have been made in the so-called quality characters of the individual plume, but in doing this no attention has been given to the number of feathers which one bird produces as compared with another, and therefore no numerical change has taken place. It is a good instance of the principle that no progress is ever made as a result of indiscriminate breeding, unless a character has some selection value, or mutations are taking place.

Cross-bred Ostriches. Seeing that the northern and southern birds have the same average number of plumes and are a mixture of heterozygotes, no change is to be expected in the number of plumes on crossbred chicks compared with what would be procured by mating two northern or two southern birds. The table given below is an example of the results which have been obtained. The arithmetical mean of the parents is 36.24 and of the chicks $36 \cdot 28$, but for a large: series the average is 36.31 which agrees more closely with that of the two races. 


\section{Crossing the North and South African Ostrich}

A hint at factorial purity is indicated seeing that the extremes 33,34 and 39 are not represented.

\section{TABLT VII.}

Number of first-rowo Plumes on Cross-bred Chicls from mating a North African osck with a South Afirican hen.

\begin{tabular}{|c|c|c|c|}
\hline \multicolumn{4}{|c|}{$\begin{array}{l}\text { North African cock, No. } \\
\text { South African hen, No. } 22\end{array}$} \\
\hline \multicolumn{4}{|c|}{ Chichs: } \\
\hline 1 & No. 300 & & \\
\hline 2 & No, 301 & $\ldots$ & \\
\hline 3 & No. 315 & $\ldots$ & \\
\hline 4 & No. 316 & $\ldots$ & \\
\hline 5 & No. 318 & $\ldots$ & \\
\hline 6 & No. 320 & $\ldots$ & \\
\hline 7 & No. 321 & $\ldots$ & \\
\hline 8 & No. 322 & $\ldots$ & \\
\hline 9 & No. 323 & $\ldots$ & \\
\hline
\end{tabular}

Right Wing Left Wing

$37 \quad 36$

$36 \quad 36$

$36 \quad 36$

$\begin{array}{ll}30 & 36 \\ 38 & 37\end{array}$

$36 \quad 37$

$37 \quad 36$

$35 \quad 36$

$36 \quad 36$

$36 \quad 35$

Survival of 42-plumed Ostrichès. Among the Cape birds in the Grootfontein flock two ${ }^{1}$ have been discovered with 42 plumes to the first row, though the rest have the usual average of about 36. At first it seemed as if two distinct strains of ostriches were represented in South Africa, as compared with the single strain in North Africa, one with approximately 36 plumes as the average and another with 42. 'The countings on farmers' birds have however given no support for this view; they have disclosed no individual bird exceeding 40 plumes, nor any influence from a 42 -plumed strain. Hence it is concluded that the occurrence of ostriches with 42 plurnes is altogether exceptional among Cape birds, and has had no recent influence on the general average. Likewise none of the Nigerian birds has more than 39 plumes, nor any of the chicks reared from them; so the influence of a 42-plumed strain is non-existent in North Africa.

As regards their origin it is manifest that the 42 -plumed birds represent a distinct departure from the ordinary 36 -plumed birds. Were no other evidence available the high number might be looked upon as a meristic mutation and, as will be proved later, the birds give progeny with such high numbers as to show that the extra plumes are not merely the extreme limit of a fluctuating series but have a factorial value. They

1 Of the two original birds one has since met with an accident and died. The birds were procured several years ago from two farmers widely apart, without any suspicion of their number of plumes. It is noteworthy that thongh search had since been made among the same flock yet in neither case has another 42-plumed bird been found. 
have also been considered in the light of reversions to an earlier ancestry, but fuller consideration leads us to account for them otherwise. Recent observations, to be fully described in a later paper, have shown that the ostrich presents us with numerous stages indicating the course of the degeneration which the wings and legs have undergone up to the present, as well as the course likely to be followed in the future. Survivals of many ancestral characteristics are to be found among the plentiful material now available for study. Thus, while ordinarily only one incomplete row of under-coverts is present, a farmer's strain exists in which a second row of under-coverts is almost complete, and several members of a third row also occur; and single members of both rows are occasionally met with on other birds. All stages are to be found from a complete row of under-coverts to the usual one where 8 to 10 are wanting at one end of the row (Pl.VII, fig. 2); and conditions of a like nature are to be met with in the second row of upper-coverts. Vestigial down is to be found on most ostriches over the wings and tail, though it is usually stated to be absent. Further, while usually buried in the flesh of the wing, the third digit sometimes bears a second phalanx and projects freely from the surface, and even bears its own plumes, a primitive condition suggestive of the fossil bird Archaeopteryx. The claw is usually absent from the small, fourth toe of the foot but still survives in a few; while the scales on the middle toe show the beginnings of loss by one or two breaks in their continuity (Text-fig. 2, p. 182). Experiments hitherto carried out all indicate that the individual losses have proceeded as retrogressive mutations, on definite factorial lines and in well-defined, determinate directions.

In view of all these survivals of many of the earlier characteristics of the ostrich the 42-plumed. bird may with good reason be regarded as a survival of a stage when the average number of plumes to the wing was larger than at present. On this interpretation the 36-plumed birds of to-day are to be considered as degenerate in the number of wing quills, as they are in many other respects. The practical endeavour is now being made to build up a pure strain of ostriches bearing 42 plumes, for with the increase of the other rows of plumes in correlation with the wing quills it becomes possible to provide the farmer with an ostrich giving about $25 \%$ more plumes than he receives from his birds at present, the "quality points" being also of the highest. The demonstration below that the high number is not merely the extreme of a fluctuating series, but is factorial in its nature, renders this possible. Whether by continued selection the number 42 will ever be exceeded 


\section{Crossing the North and South African Ostrich}

is doubtful, seeing that the factors for any higher number have probably been altogether lost to the race, even if they were ever present in the ancestral ostrich.

Table VIII shows that when the 42-plumed southern cock is mated with various North African hens of the 36 strain the average number of plumes in the progeny is practically intermediate, namely 39.56 , the lowest number being 37 and the highest 42 ; they do not regress to the general averuge. The numbers form an approximately normal curve with the mode at 40 . None of the birds hitherto employed as breeders can be deemed "pure" as regards the number of plumes; and the 42 plumed bird is probably heterozygous like the rest; hence the fluctuating series represented below.

\section{TABLE VIII.}

Number of first-row Plumes on Cross-bred Chicles from mating a 42-plumed Sonthern coclo and 36-plumed Northern hens.

\begin{tabular}{rlcc|cccc} 
& \multicolumn{3}{c}{ Right Wing Left Wing } & & \multicolumn{3}{c}{ Right Wing Left Wing } \\
1 & No. 226 & 42 & 41 & 13 & No. 311 & 40 & 40 \\
2 & No. 228 & 39 & 40 & 14 & No. 230 & 41 & 40 \\
3 & No. 229 & 41 & 42 & 15 & No. 232 & 39 & 41 \\
4 & No. 242 & 40 & 40 & 16 & No. 233 & 41 & 42 \\
5. & No. 243 & 39 & 40 & 17 & No. 234 & 42 & 40 \\
6 & No. 302 & 37 & 38 & 18 & No. 237 & 40 & 39 \\
7 & No. 303 & 38 & 38 & 19 & No. 238 & 39 & 38 \\
8 & No. 304 & 40 & 40 & 20 & No. 1 & 39 & 38 \\
9 & No. 307 & 38 & 38 & 21 & No. 2 & 39 & 39 \\
10 & No. 308 & 40 & 39 & 22 & No. 3 & 38 & 39 \\
11 & No. 309 & 37 & 39 & 23 & No. 4 & 40 & 41 \\
12 & No. 310 & 38 & 39 & 24 & No. 5 & 41 & 40
\end{tabular}

Experiments are being undertaken to determine how far it is possible to extract numerically pure lines, especially as regards the two extremes 33 and 42, but progress is necessarily slow. Until this has been done full proof will be lacking that each plume has its own factorial representation, though all the evidence points in this direction.

The 33-plumed birds represent the extreme of the loss of wing quills which has taken place in the ostrich of to-day compared with the maximum of 42 plumes. If, as we seem bound to suppose, some intrinsic influence is at work within the germ plasm inducing slow retrogressive changes, it appears not unlikely that by in-breeding pure 33-plumed birds it will be possible to increase the action of the degenerative force and produce a still further loss of plumes. By selection it should be possible to control the further evolution of the ostrich with regard to the number of its plumes. 
As noted earlier, farming practice has established as clearly as could be expected that the different "points" of the plurnes are factorial in their behaviour, and as they vary in the various strains a separate germinal representation for each may be assumed. Even such a simple structural part as the central shaft of the feather shows many different types which appear either distinct or as intermediates in crosses. The length of the barbules and their closeness on the barbs are also matters of much economic importance in determining the "density" of the plumes, and the farmer never questions their distinctness in breeding. At the present stage of the ostrich industry, where crossing is practised to such a high degree, the factorial analysis of the individual plume would be a prolonged undertaking, but will become feasible as the farmer finds himself in a position to build up pure strains.

\section{Scutellation of Middee Toe.}

Along the front of the tarsus extends a series of large, nearly rectangular scales, which in most cases continues uninterruptedly to the end of the big middle toe. Over the leg the contiguous edges of the scales simply meet, but they are imbricated where the tarsus joins the toe and also over the latter, thus allowing for the bending movements of the toe during walking and running. Along the tarsus the scales retain approximately the same size, but at the junction with the toe they usually become somewhat smaller, enlarging again distally. Occasionally a distinct break in the continuity occurs at the joint, several of the large scales disappearing and being replaced by insignificant ones like those which cover the surface of the limb generally; and in rare cases a second break in the continuity takes place over the joint about the middle of the toe, thus giving a proximal and distal series of digital scales (Textfig. 2, p. 182).

The number of scales fluctuates in different individuals, and also on one limb as compared with the other; and occasionally irregularities are introduced owing to single scales being partly subdivided. At the breaks the large scales tend to pass insensibly into the small scales of the limb, hence any enumeration is only approximate. A few countings are given in Table VIII, p. 183.

The break in the continuity occurs rather rarely, especially in southern ostriches. Out of 20 Cape birds of mixed breeding only one showed an interruption, while in 20 mixed Nigerian birds a single break occurred in three cases and a double break in two. As the figures in 


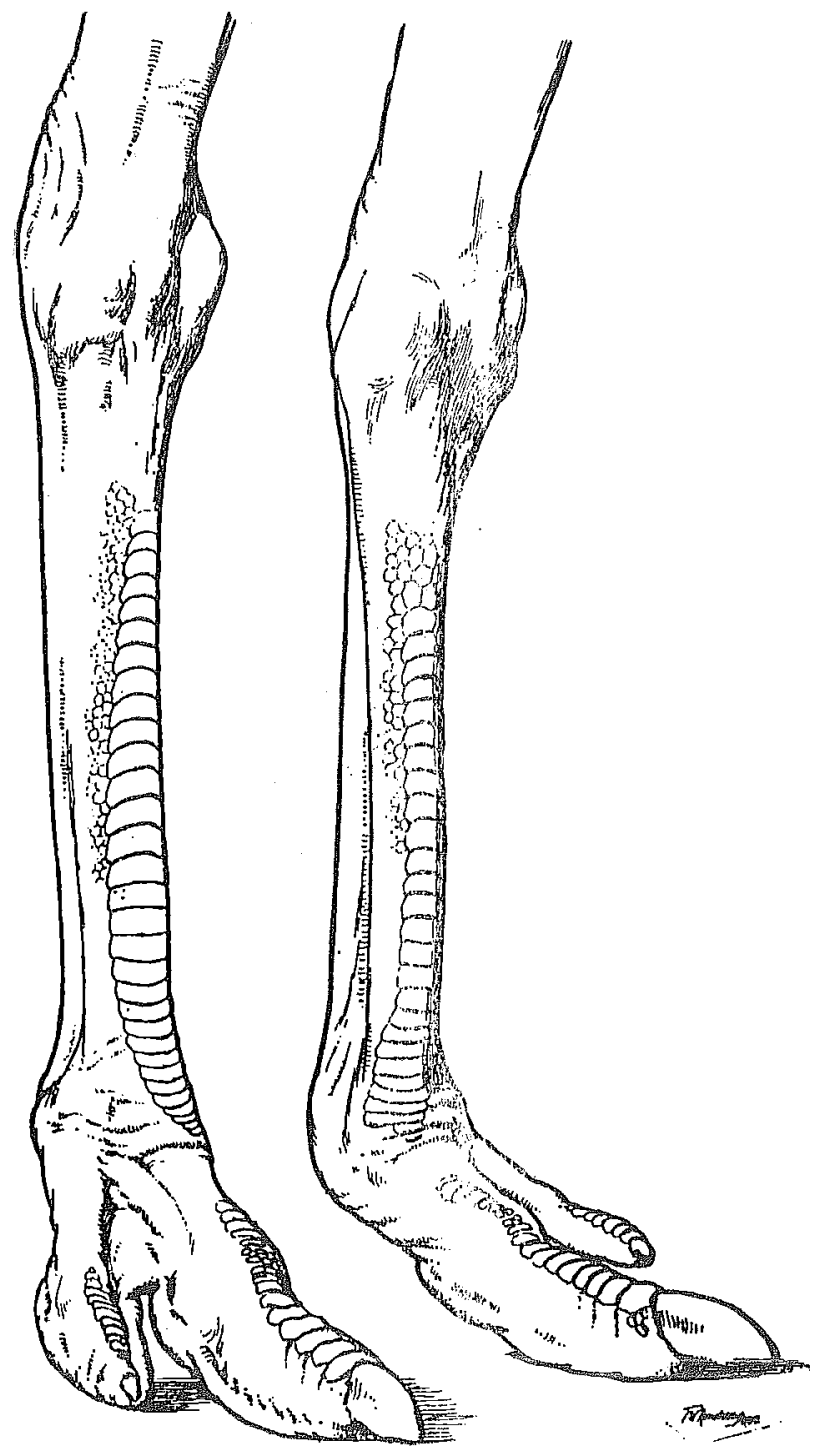

Text-fig. 2 . Tarsi and feet of Northern Ostrich. The seutellation shows a strong break between the tarsus and the large, inner third toe and the beginning of a second brealk over the middle juint of the toe. The small, outer, fourtli toe bears only a few scales and the claw sliown is unusually well developed. 
TABLE VIII.

Number of Scales in 'T'arso-pedal Scutellation.

A. Contintous :

1
2
3
4

Right Tarens and Toe

53

55

57

B. With one break :

58

$\begin{array}{ll}\text { arsus } & \text { Toe } \\ 27 & 16 \\ 28 & 17\end{array}$

C. With two breaks

\begin{tabular}{cccc} 
& \multicolumn{3}{c}{ Toe } \\
1 & 29 & 5 & 8 \\
2 & 30 & 5 & 9 \\
3 & 32 & 6 & 9
\end{tabular}

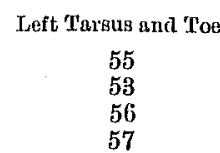

$\begin{array}{cr}\text { Tharsus } & \text { Toe } \\ 27 & 17 \\ 30 & 19\end{array}$

\begin{tabular}{crr} 
Tarkits & \multicolumn{2}{c}{ Toe } \\
29 & 5 & 8 \\
31 & 6 & 9 \\
31 & 7 & 11
\end{tabular}

Table VIII show, the breaks represent a definite loss of scales. Taken along with the other facts of degeneration in the foot, the losses are without doubt to be regarded as the first evidence of degeneration in the middle toe of the ostrich, the first, second and fifth having already disappeared and the small fourth being well on the way. The breaks evidently represent independent unit characters, retrogressive mutations, in course of introduction within the whole race, the process having gone a little further in the northern ostrich than in the southern.

In all ostriches the tarsal scutellation is now distinct from that over the small toe, only 8 to 10 scales occurring distally (Text-fig. 2). Comparison with other birds would, however, lead one to expect that the two series were originally continuous ${ }^{1}$, as they are still in the great majority of ostriches with regard to the middle toe.

Breeding experiments prove that the breaks between the tarsus and middle toe are germinal in their nature. Where no break occurs in either of the parents the progeny also show no loss of scales. Thus in 13 cross-bred chicks from a southern cock and a northern hen, both with a continuons scutellation, ro loss of scales occurred. When however one of the parents bears a break and not the other, then, as indicated below, approximately one-half of the chicks displays the loss, proving that the factor for the break is dominant but that the germ plasm is simplex or heterozygous with reference to it.

1 At extensive series of birds' feet is shown ou p. 425 of Sedgwick's, Students' 'Text-book of $Z$ Zology, Vol. ז. 1905, where however the soutellation of Struthio camelus is erroneonsly represented, the sarles of the small toe being depicted as continuous with those of the tarsus. 
TABLE IX.

Scutellation in Parents and Chichs.

\begin{tabular}{|c|c|c|c|c|}
\hline Parents : & & & No Brealk & Breal \\
\hline $\begin{array}{l}\text { North African } \\
\text { South African }\end{array}$ & & $\begin{array}{l}\text { o. } 78 \\
\text { o. } 225\end{array}$ & $\stackrel{x}{-}$ & $\bar{x}$ \\
\hline Cross-bred Chicks: & & & & \\
\hline No. 314 & $\ldots$ & $\ldots$ & $x$ & - \\
\hline No. 315 & $\ldots$ & $\ldots$ & $x$ & \\
\hline No. 316 & $\ldots$ & $\ldots$ & - & $x$ \\
\hline No. 318 & $\ldots$ & $\ldots$ & - & $x$ \\
\hline No. 319 & $\ldots$ & $\ldots$ & - & \\
\hline No. 320 & $\ldots$ & $\ldots$ & _- & x \\
\hline No. 321 & $\ldots$ & $\ldots$ & $x$ & - \\
\hline No. 322 & $\ldots$ & $\ldots$ & - & $x$ \\
\hline No. 323 & $\ldots$ & $\ldots$ & $x$ & \\
\hline No. 300 & $\therefore$. & $\ldots$ & $x$ & - \\
\hline No. 301 & $\ldots$ & $\ldots$ & - & $x$ \\
\hline
\end{tabular}

The heterozygous condition with regard to the break is what would be expected, assuming that the character is one which is in process of introduction within the race, and that it behaves in Mendelian fashion. At present the mutation is found in comparatively few individuals, and in a state of nature there is little chance that a bird showing the break would mate with another in a like condition, but rather with one having the scales continuous. If the change first took place in a homozygous duplex manner in a few individuals there is small likelihood that these would mate with others in like condition, but with nulliplex individuals. The first crosses would be dominant and simplex, and these mating with other nulliplex birds would give half simplex dominants and half nutlliplex, which is what the experiments indicate. As shown below, certain significant results have been obtained on in-breeding some of the crossbred birds.

\section{TABLE $\mathrm{X}$.}

Scutellation in $F_{2}$ chicks compared with Parents and $G_{r}$ randparents.

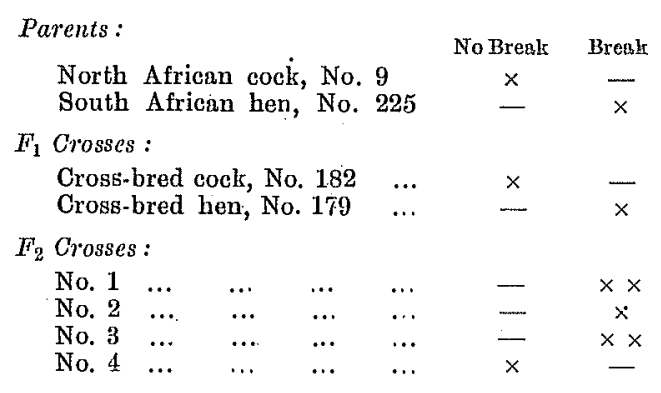


In this case the original parents were a North African cock without any loss of scales and a South African hen with a single break. Of the four offspring reared three are without the break while it occurs in No. 179, the hen used in the experiment. From the mating of brother and sister four chicks were hatched, two of which had two breaks in the scutellation, one had only a single break and one had no break. The result may be regarded as highly suggestive that the inherent tendency towards the loss of scales can be accentuated by in-breeding, and degeneration thus accelerated along definite prescribed lines; for after the single break the next step in the loss is a second break over the middle of the toe. In the course of the investigations it has become evident that an inherent tendency exists in the ostrich towards the loss of various parts of the fore and hind limbs in a continuous determinate direction, as well as of its plumage, and it is not unlikely that by in-breeding the degenerative tendency can be accentuated. The accumulation of fuller data must however be awaited before the suggestion as regards the loss of scales can be regarded as more than tentative.

\section{Claw on Fourth Toe.}

The claw on the small, fourth toe has for the most part disappeared from the ostrich, though it is occasionally present, more often on North African than on South African birds (Text-fig. 2). In 25 mixed northern birds it occurred on six specimens and was wanting on the others, while in 20 mixed southern birds it was found on only one individual. Everywhere it is feebly developed, especially by comparison with the big claw on the middle toe, and is always non-functional, never reaching the ground. Where best formed it projects for about half an inch from its socket, while at other times it is almost hidden in the integument, and can scarcely be felt with the finger; but all intermediate sizes can be obtained. Usually it is equally developed on both the right and left foot, though sometimes a difference is observed.

In crosses where both parents are without the claw the progeny are also devoid of it, though in a nest of 16 chicks from clawless parents a distinct claw appeared in one (Cross-bred No. 304). Where however one parent is clawed and not the other it appears in about half the progeny, showing that the clawed birds are dominant heterozygotes. Out of a total of 36 chicks hatched from breeding pairs, where one parent was clawed and not the other, the numbers were actually equal, 18 chicks clawed and 18 unclawed. 


\section{Crossing the North and South African Ostrich}

Thus, as in the case of the loss of scales over the big toe, the evidence is conclusive that the presence of the claw follows the Mendelian proportions for heterozygotes when breeding takes place. Where the parents are nulliplex as regards the factor no claw usually appears in the progeny, but where a clawed individual mates with a clawless the structure appears in practically half the progeny.

With the small proportion of clawed to clawless individuals among both northern and southern birds it is to be expected that most of the clawed ostriches will be heterozygous as regards the factor for the claw for in a mixed assemblage the chances of a clawed bird mating with another clawed one are very remote. A clawed bird will almost certainly be the progeny of one clawed and one clawless parent, and hence will be a simplex dominant, and when in turn mated with a non-clawed bird will give progeny half of which are again simplex clawed and half clawless.

\section{Discussion.}

The northern and the southern ostrich illustrate in a clear manner. how distinct species of animals may arise on the basis of germinal or factorial changes. It may be assumed that both are the descendants of an original stock in which the characters were all alike, and that in the course of time alterations have taken place in the germ plasm which give the marked differences now separating the two. Whether the changes have any adaptive value or not will be discussed later. Considered as a whole the broad genetical conditions are fairly simple, as no other representative of the Ratitae exists in Africa with which individual ostriches could have hybridised. As we know the two-toed ostrich to-day, it may be assumed to have evolved entirely within the continent, though in Tertiary times extending into Eurasia as far as Southern India, fossil remains having been found in the Siwalik deposits. That the two species had a common origin, and are not yet far apart, may be inferred from the fact that they interbreed and the offspring are fertile, also that similar degenerative changes are going on in the ger'm plasm of each (parallel mutations).

Factorial Constitution. The results from the crossing of the two species, though admittedly very incomplete, afford certain evidence as to the present germinal constitution of the ostrich, and indicate directions along which changes are taking place. Everything points to the distinctive characteristics of the two species as having separate factorial 
representation in the germ plasm. The bald patch is a unit character which has appeared in the northern without any corresponding change in the southern bird. In all the individuals used for crossing it behaves in a homozygous manner, showing that it has become fully established throughout the northern race. It supports the presence and absence conception of genetic factors ; the factor for baldness is present in duplex form in the germ cells of the northern ostrich but is absent from those of the southern. In cross-breds of the first generation it is simplex dominant, and in cross-breds of the second generation it is found to segregate.

The dimensions and colours of the ostrich, as well as the various features of the egg, have manifestly a more complex factorial representation than the bald patch. In the ancestral ostrich the factors for each of the characters were doubtless common to all the individuals, but germinal divergence has since taken place. The cross-breds serve to establish that each species now has its own separate factor or factors controlling its size, for those of the one are neither dominant nor recessive to those of the other. They do not constitute an alternative pair, a presence and an absence, as in the case of the bald patch. Hence in the zygote resulting from the cross-mating the simplex factors for both races are represented, the factor for the small size of the southern bird and that for the large size of the northern. In the resulting soma the two sets of forces are, as it were, each independently striving for expression, and naturally the individual cannot be both sizes at the same time, but appears as an intermediate, a resultant of the interaction of two distinct tendencies, one from the northern parent and one from the southern.

Similarly with the body colours. Each species may be deemed to have its own distinctive factors controlling its colours, for in crosses they do not behave as alternative pairs. In the cross-bred bird each factor endeavours to exert its pure specific influence, the result being a combination of the two, a colour which is intermediate and partakes of the nature of both; sometimes one factor may gain a slight ascendency and sometimes another. The same conclusions as to factorial distinctness have been arrived at with regard to the various characters of the eggs which appear as intermediates in the $F_{1}$ crosses. The exact gametic constitution, as regards the dimensions, colours, and eggs, can however be determined only after a number of chicks of the second generation have been reared.

The factorial representation for the plumes must be complex to a Journ, of Gen. viII 
still further degree. As already indicated, the numerous "points" in the feather to which the farmer attaches importance behave in breeding practice as if each were under separate control. On the other hand we have abundant evidence that in ordinary breeding, and also in degeneration, each plume usually acts as an independent whole, as if some factor or group of factors controlled it in its entirety, irrespective of its numerous component factors. A complexity is however introduced by the presence of vestigial, imperfectly formed feathers, a few of which are sometimes found beyond the last fully developed plume in a row, and also as vestigial down on the wings and tail. Where vestiges occur during degeneration we can only surmise that the factors which control the whole plume may drop out piecemeal. They show that meristic structures do not always appear or disappear in their entirety. We may have a part of a feather as well as a whole.

Among the mixed assemblage of ostriches of the present day the genetic factors controlling the number of wing plumes in each bird may be regarded as heterozygous, for from any pairing we get a fluctuating series around some mode, less wide in some cases than in others; but if, as seems likely, it is found possible to extract pure lines for each of the numbers from 4,2 to 33 these will then breed true and may be expected to be homozygons.

The loss of scales from the middle toe evidently represents a germinal change which is actually in progress in both northern and southern birds at the present time. It proceeds along parallel lines in both races, its first manifestation being a loss of scales at the joint between the tarsus and toe and then another over the middle of the toe. The breaks represent a loss of structural parts of the foot, though they are dominant over continuity. As yet the germinal change involved in the first break has affected only a small proportion of birds and the second break a still smaller proportion. The other facts of degeneration in connection with the foot, the claw and scales over the small toe, and the loss of three toes, are taken to justify the assumption that the breaks represent still further degeneration which is in progress for the ostrich race as a whole. If, when first introduced, the change is a homozygous one, there is small likelihood that, in mating, the homozygote will meet with another homozygote. Until the mutation is introduced among a considerable number of birds the chances are that pairing will take place with a nulliplex individual, in which case all the progeny will be heterozygotes; these in turn are more likely to pair with a nulliplex, and as regards the break the offspring will be simplex dominant and nulliplex in equal numbers. 
As already proved both the northern and the southern birds showing the mutation behave as heterozygotes in crosses.

Like the loss of the scales from the middle toe the loss of the claw on the fourth toe is a degenerative change in progress within the ostrich race as a whole; likewise it is germinal in its nature, and in crosses follows Mendelian lines. Also it can readily be admitted as part of an established degenerative scheme which has been going on in the foot for a vast period seeing that the first, second and fifth toes have already disappeared. The loss is however an individual one, not one affecting the race as a whole simultaneously; but compared with that of the scales the absence of the claw has reached a stage where by far the majority of the race are affected. The loss of the claw factor may be deemed to take place de novo in individual birds, and in course of time has affected larger and larger numbers. In crosses the presence of the claw is dominant over its absence, but, from the small proportion of individuals now possessing one, the chances of a clawed bird mating with another clawed bird must be very remote; hence, as the investigations prove, the few showing the claw are heterozygotes.

The fact that a germinal change, such as is involved in the loss of the claw or the scales on the toe, occurs in individual birds anywhere throughout the continent, strongly suggests that, whatever the degenerative influence may be, it acts on the germ plasm of the ostrich as a whole, wholly irrespective of environmental conditions. It gains ezpression de novo at different times in different individuals, but in the end affects all the members of the genus, as had happened in the case of the losses already sustained. The gradual loss of the scales, as well as that of the claws and feathers, indicate that retrogressive evolution is taking place piecemeal on strictly factorial lines, but in a continuous determinate manner as regards the race. If, as seems likely, we are to regard the baldness of the northem bird as the first step in the loss of the head plumage then we have an instance of the retrogressive changes affecting only one of the species (divergent mutations), while the loss of the scales and claw is in progress for the entire race (parallel mutations).

The parallelism of the changes going on in both species of ostrich is readily understood if we regard the two as having a common origin from the same germ plasm, with all its inherent tendencies. Many of the parallelisms of evolutionary changes found in other forms of life may also be deemed to be indications of a distant common origin for part at least of their germ plasm. Darwin in his Origin, p. 179, remarks: "As all the species of the same genus are supposed, on my theory, to have 
descended from a common parent, it might be expected that they would occasionally vary in an analogous manner:" All the parts of the germ plasm may be held to be the same for any "pure" species; some parts are changed and give us the distinctions between species; other parts differ in producing generic separations, and still more fundamental parts in giving ordinal, class and phylar distinctions; but corresponding changes may take place in the germ plasm which remains common to phylum, class, order or gênus and so give rise to parallel mutations, the Analogous Evolution of Prof. H. F. Osborn ${ }^{1}$, while divergent changes in the common germ plasm would produce Polyphyletic Evolution. In the ostrich specific changes have taken place, and others embracing the genus are in progress.

Adaptive Value of Changes. We may briefly consider whether the changes set up in the germ plasm, and expressing themselves in the soma, have any adaptive significance in the life of the ostrich. Following largely the teachings of Bateson and Morgan, few writers now are prepared to admit that germinal changes are a response to external environmental influences, or have appeared in response to some need of the organism, or have necessarily some selection value; rather it is held that they are dependent upon some intrinsic cause which may vary in different cases. Though we may not know much as to the conditions under which the changes are brought about till once effected and manifested in the body, we may discuss the question of their utility or otherwise to the individual and their influence on the evolution of the race.

The bald head patch on the northern ostrich is probably as neutral in its effect on the bird as it is possible for any character to be; it is impossible to think of it as exerting any beneficial or harmful influence compared with the feathered condition in the southern bird. Both races are equally successful. It should probably be regarded as the first step in the loss of the head covering, thus introducing plumage degeneration to this region of the bird, following upon losses which have already been effected over the legs, wings and body and which are presumably still in progress. In this case the baldness raises the whole question of the adaptive significance of the loss of plumage going on in the ostrich, only the bare facts of which can now be noticed. In chicks the outer surface of the leg, from the knee joint to the ankle, is well covered with feathers which practically all drop out before maturity is reached. The under

1 H. T. Osborn, The Age of Mammals, Macmillan and Co., 1910, pp. 29-34. 
surface of the wing is now practically naked. Only one row of undercoverts persists, and it is hardly ever complete, while rare survivals of members of the second and third rows indicate that the under surface was at one time well covered. The wing quills and upper $\cdots$ coverts are many less in number in some strains than in others, and the under covering of down for the body generally has all but disappeared, vestigial plumules appearing only around the base of the large feathers of the wing and tail. Probably no bird is at present so naked as the ostrich.

It is questionable however whether the loss of plumage hitherto has any serious influence on the well being of the ostrich. It is not incompatible with its present existence. But should the losses continue to a much further degree the absence of a protective covering may begin to be felt; while should the number of wing quills become still further lessened their inability to cover the usual quantity of eggs (12 to 16) during incubation may affect the number of chicks reared.

It is likewise impossible to ascribe any selection or utilitarian value to the colour differences between the northern and the southern ostrich. The light colour of the chicks, young birds and hens of the former compared with the dark colour of the latter can hardly be regarded as either advantageous or disadvantageous. The intense scarlet nuptial colouration of the northern cock as contrasted with the restricted scarlet of its southern rival has already been shown to give it no preference in the eyes of its sombre mate. On the natural veld it might possibly add to its conspicuousness, supposing any greater display value on the African plains could be thought of than that of an ordinary cock with his intense black body plumage, white wings, white neck and light legs'.

In like manner the marked differences associated with the egg of the two races can scarcely be deemed to have any adaptive value. The bigger northern bird may be expected to produce a larger egg than its smaller southern relative, but from a selection point of view nothing in reason is to be said in favour of its rounder shape, smooth surface and absence of pitting, in comparison with the more oval shape and pitted surface of the other. Both are equally successful in artificial as well as natural incubation.

On mechanical grounds some advantage may accrue from the loss of the fourth toe, the claw of which has almost disappeared from the race,

1 Ex-President Roosevelt in African Game Animals, bas given much consideration to the question of protective colouration and considers (p. 181) that "Cock ostriches always show jet black, and are visible at a greater distance than any of the common game; the neutral tints of the hens malking them far less conspicuous." 
just as the loss of the first, second and fifth toes has for long conferred a mechanical advantage by transferring practically the whole of the leg movements directly to the big middle toe. If however the degenerative forces are so relentless as they appear to be and should next begin to attack the big toe there could then be no question. of the ultimate influence of the genetic changes upon the well-being of the bird, for with the loss of all its toes it is inconceivable that the extinction of the ostrich would not be imminent. While the losses of the scales in the case of the single break on the middle toe and the still rarer double break are deemed to be the first steps in this direction, it is conceivable that they are for the time being advantageous in the flexions and extensions of the toe.

On the whole then no evidence is forthcoming that the differences between the northern and the southern ostrich have arisen because of any direct utilitarian consideration; and the same can be said of the retrogressive changes common to both. Having appeared, they may come to have an adaptive value; but even for this there is no support except perliaps as regards the loss of the toes. On the other hand there is much to indicate that, if the degenerative losses continue in the various directions already initiated, we may look forward in the dim future to the sad spectacle of a wingless, legless and featherless ostrich, if extinction does not supervene.

As already remarked it is impossible to resist the conviction that we have in the ostrich some intrinsic influence, slow but continuous in its action, which is bringing about the gradual loss in piecemeal fashion of the various parts of the wing and the legs as well as of the plumage, wholly irrespective of external influences or adaptive considerations. The losses are separate mutative changes so far as the individual is concerned, yet the result for the race is continuous, determinate degeneration along several directions. If, as seems to be the case, the losses hitherto have no adaptive value, then natural selection is in no ways concerned with them, though it will become-operative when degeneration has proceeded so far as to interfere with the ordinary activities of the bird. Some adaptive value may be ascribed to the loss of the three toes from the foot, and also to that of the fourth which is in progress, yet it could hardly be conceded when; the same degenerative tendency continuing, the only remaining toe is attacked. It is manifest that an evolutionary change may be advantageous up to a certain point but disastrous when continued beyond.

The Nägelian idea that evolutionary changes have taken place as 
a'result of some internal vitalistic force, acting altogether independently of external influences, and proceeding along definite lines, irrespective of adaptive considerations, seems to be gaining ground at the present time arnong biologists ${ }^{1}$. The degeneration phenomena presented by the ostrich appear to constitute as clear an example in support of it as could be adduced, while the genetical results seem to afford what has hitherto been lacking, namely, the direct application of mutation and Mendelian principles to continuous deterninate changes, such as confront the comparative anatomist and the palaeontologist. The main evolutionary conception associated with mutation is fortuitous discontinuity, but in the ostrich we perceive how discontinuous changes in the individual may proceed along definite lines and result in determinate continuous evolution for the race as a whole. The loss of scales or single feathers in individual birds may seem to be nothing more than haphazard chance occurrences, but when considered for the race they indicate an orderly progress towards definite end results.

Establishment of Characters. If none of the changes, which have taken place between the northern and southern ostrich have any selection value we may well enquire how the differences have gaxday become established. Undoubtedly geographical isolation as regards North and South Africa has played some part. Whatever intermediate forms may be found in the intervening areas, the ostriches in the more extreme parts of the continent must have evolved independently on one another for long ages, though not to such a degree as to bring about infertility between them. Some changes, such as the bald patch, and those connected with the size and colour of the body and the nature of the egg, are now distinctive between the two races, while others, such as the loss of plumage, the loss of the claw on the small toe, and of scales on the large toe, are common to the ostrich race as a whole.

Assuming the characteristics for the race to have been the same originally, and that the distinguishing features of to-day have no selection value, we may first enquire how, for example, such a unit character as the bald head patch has come to be dominant and duplex for the northern species, while altogether absent from the southern. On the factorial theory of variation we assume that some definite, hereditable change tools place in the germ plasm of the northern ostrich, as a result of which the feathers fall out from the top of the head at a certain age. If we further admit that the number of ostriches for the area was con-

1 C.B. Davenport, "The Form of Evolutionary Theory that modern Genetioal Research seems to favour." Amer. Nat. Vol. L. Aug. 1916. 


\section{Crossing the North and South African Ostrich}

stant, that all were equally fertile and that breeding at random took place then a single pair of mature birds would on the average give rise to only a single mature pair: At the beginning we may allow that the mutation occurred in the germ plasm of, say, a single bird, and represented a double or duplex dose and was dominant. Such a bird mated with one in which the change had not taken place would give offspring all of which would be simplex dominants for baldness, Only two of the progeny would reach maturity and mating with two nulliplex individuals would give four mature birds of which two would have the factor simplex and two would be nulliplex. Thus on the conditions postulated the number of birds showing baldness would never increase beyond two and both would be simplex, that is, the new character would retain the same proportion throughout the history of the race. There would be no swamping of the character and no increase of individuals showing it. In the same manner if the factorial change tools place in the germ plasm of a number, $x$, of birds simultaneously, their influence on its introduction would be to the extent of $2 x$, if all the progeny were simplex. If matings took place between simplex pairs instead of between simplex and nulliplex then the result at maturity would be one duplex dominant, two simplex dominants and one nulliplex on the average for each two pairs; in other words, the mating would result for the time being in a loss of one-fourth of the number bearing the character, but the original number would be restored if the duplex dominant paired with a nulliplex, for two simplex individuals would result.

Thus under the conditions stipulated-a new character of no selection value, a stable population, free intermingling and equal fertility-conditions which it must be admitted are closely approximated in the natural life of the ostrich, the complete introduction of a new unit character in duplex form would occur only by the germinal change taking place as many times as there are individuals making up the race. On the other hand the character could be introduced in a simplex form by the change being effected in half the number of individuals. It follows that unless a new character has some selection value it cannot be bred into a race; it must be introduced de novo for each homozygous increase and half the number of times for the heterozygous increases.

As regards the bald patch therefore the germinal change must have been effected as many times as there are individuals making up the northern race, for the experiments have proved they are all homozygotes. We can scarcely conceive that the alteration would be carried out simul- 
taneously in all the individuals, presumably it affected a few at first and others gradually. For a long time in the history of the race some of the birds would be duplex for baldness, some would be simplex and the rest would be nulliplex. Mr G. H. Hardy (Punnett's Mendelism, 1911, p. 136) has shown that under conditions such as are stipulated for the ostrich the population would rapidly fall into a stable condition with regard to the proportion of the three forms, whatever may be the proportion to start witl. If the population consists of $p$ homozygotes of one kind, $r$ homozygotes of the other kind and $2 q$ heterozygotes then he points out that such a population would be in equilibrium for a particular factor so long as the condition $q^{2}=p r$ is fulfilled. The proportions which satisfy the equation are exceedingly numerous and in case of any disturbance of the equilibrium, as by the appearance de novo of the character, it will be restored after a single generation.

From the foregoing we gather how little effect under natural conditions the importation of the hundred and thirty-two northern birds would have upon the southern race if the population of the latter were stationary. If all the northern birds reached breeding age and mated with the southern they would in the end give rise to only double the number of simplex, bald-headed ostriches, and the number would neither increase nor decrease. How far the other characters-dimensions, colour and nature of the egg-would influence the southern race cannot be determined until their actual factorial values have been worked out.

The conditions represented by the loss of scales from the middle toe and the claw on the fourth toe further help in an understanding of how mutative changes are introduced into a large assemblage. It is seen that the loss of scales has occurred in individuals of both the northern and southern birds, though more frequently in the former. The change however must have appeared independently north and south, for the distinctness of the other characters, especially that of baldness, proves that no intermingling of the two species has taken place towards the extremities of the continent. Appearing at first in comparatively few individuals, and presumably in duplex dominant form, it is most unlikely that a bird having the break would mate with another showing the same loss, but rather with one in which the scutellation was continutous. The duplex bird mating with a nulliplex would give $F_{1}$ progeny in all of which the break would appear, while germinally they would be simplex. The simplex condition would tend to be retained until such time as the character became prevalent and opportunity occurred for a simplex to meet with a simplex, when a duplex condition would arise. It is significant 
however that in all cases where an ostrich showing the break has been paired with one in which it is wanting, the bird has proved itself to be heterozygous, giving progeny of which approximately half display the break and half the continuous scutellation. Thus while baldness is a mutation fully established for the northern race and germinally duplex, the loss of scales from the third toe is a mutation only partly established and germinally simplex. A character in course of introduction within a race will for a long time be mainly in a simplex or heterozygous form; later, as the mutation appears de novo in more and more individuals, the population will tend to consist of duplex, simplex and nulliplex birds, until in the end all will be duplex or homozygous.

As regards the race as a whole the claw on the fourth toe reveals conditions somewhat similar to those of the loss of scales over the middle toe, but is a character which has almost disappeared. Experiments have shown that the presence of the claw is dominant over its absence, and matings with a nulliplex individual give progeny half simplex dominant and half nulliplex, proving that the clawed individuals are heterozygotes. This again is what would be expected considering the small proportion of clawed birds, and the remote likelihood that a heterozygote would mate with a heterozygote. If only heterozygous individuals are to be found then any further loss of the factor will presumably take place as a simplex, and to be completely lost to the race the change must take place as many times as there are heterozygous birds. As for the introduction of a new character so for the loss of an existing character, it cannot be bred out under the conditions postulated, but must drop out germinally.

Specific distinctness of Northern and Southern Ostrich. Whether the northern and the southern ostrich are to be regarded as separate species, or only as sub-species or varieties of a single species, raises the everrecurring, but undefinable question as to what constitutes a species. In the foregoing we have available all the data which the systematist could possibly desire to enable him to reach a decision. A germinal character, baldness, occurs in one, but is wanting in the other, while the dimensions and colours of the body as well as certain features of the egg are also distinctive and germinal. The characters are retained when the members of one race are subjected to the same environmental conditions as the other, showing they are not dependent upon external circumstances. They can all be regarded as distinct elementary characters in 
the De Vriesian sense, and the combinations might well be held to warrant us in regarding the two as specifically distinct.

On the other hand the birds are proved to interbreed freely, and the offspring are fertile, both inter se and with the parental forms. The fact that similar degenerative processes-loss of plumage, scales and claws-are proceeding in both also points to a close germinal relationship. In the opinion of many systematists the physiological fact of fertility alone would be deemed to justify specific unity.

The ostrich ranges over all the habitable parts of Africa and there is every likelihood that in intermediate areas between north and south a mingling of the two races goes on, producing a mixed population, composed of all possible combinations of the two sets of characters. Thus in the East African Ostrich, S. massaicus, as the writer has found in visiting the ostrich farms in British East Africa, the colour of the hen and immature cock is a cream yellow while the mature cock has the head, neck and legs scarlet, and the birds are somewhat larger than the southern. The bald patch is present and the eggs are pitted. The Somali Ostrich, S. molybdophanes, is described as a smaller, darker bird than the southern, but the bald patch is wanting, and the colouration is like that of the southern and the eggs are pitted.

If the entire ostrich population of Africa were gathered together we are probably justified in thinking that all intermediate forms would be forthcoming between typical northern and sonthern birds. An exception would occur however in the case of the bald patch, for however much inter-crossing had taken place the character would never be intermediate, but would be wholly present or absent; and though the dimensions, colours and egg characters appeared in varying intermediate degrees as a result of crossing we should still have the knowledge that their distinctive nature could be extracted by selective breeding. When discussing intermediates the possibility of segregation should always be borne in nind. In the present instance, where all the facts are known, intermediate forms grading from one species to the other have no direct bearing on the question of specific distinctness. Among the Afican fauna especially, experimental breeding would probably establish that many so-called species and sub-species, often founded upon one or a few specimens, are in reality intermediates or hybrids of other species.

So long as we have the facts before us it is of small moment whether we regard the northern and southern ostriches as distinct species or not. It becomes a matter of individual predilection whether greater importance should be given to somatic differences or to physiological 


\section{Crossing the North and South African Ostrich}

similarity. Without being biassed in either direction it appears to the writer to make for convenience to regard them as distinct under the names bestowed by Linnaeus and Gurney.

\section{DESCRIPTION OF PLATE VII.}

Fig. 1. Outer surface of fore-wing of ostrich, with plumes clipped off, to show arrangement of wing quills on upper (post-axial) border and rows of upper-coverts. The olaw on the bastard wing is not visible.

Fig. 2. Under surface of fore-wing of ostrich which is naked except for the single, incomplete row of under-coverts.

Fig. 3. Egg of North African ostrich (to the left) and South African ostrich (to the right). 


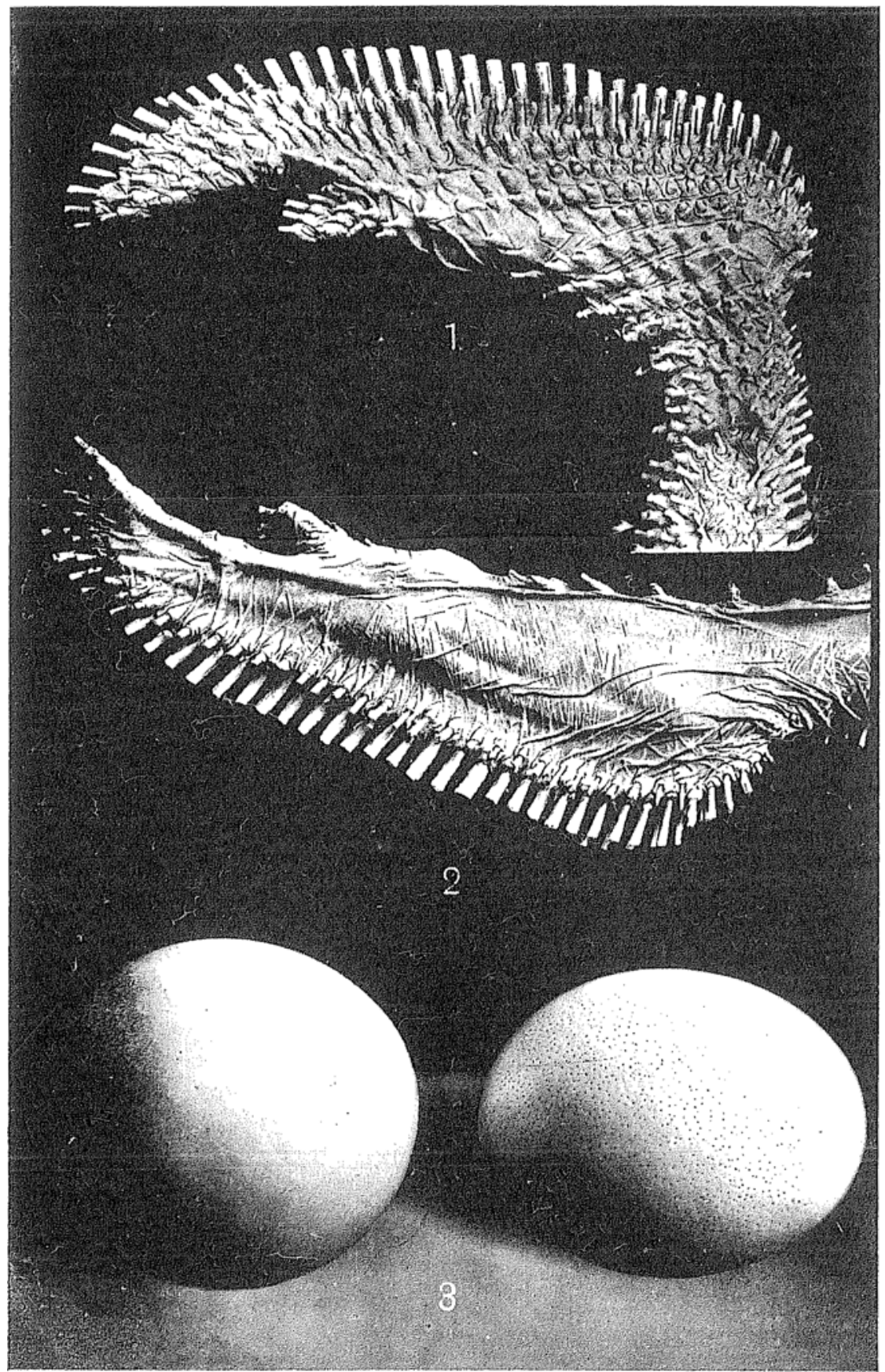

